\title{
Diseño y Validación de los Cuestionarios de Representaciones de Justicia Social para Estudiantes de Educación Secundaria (CRJSES) y para Profesores (CRJSP)
}

\author{
Design and Validation of the Social Justice Representation \\ Questionnaires for Secondary Students (SJRQSS) and for \\ Teachers (SJRQT)
}

\author{
Vanesa Sainz ${ }^{1}{ }^{*}$ \\ Liliana Jacott ${ }^{2}$ \\ ${ }^{1}$ Universidad Francisco de Vitoria, España \\ ${ }^{2}$ Universidad Autónoma de Madrid, España
}

\begin{abstract}
Se describe el proceso de construcción y validación de dos instrumentos destinados a evaluar las representaciones que estudiantes y profesorado tienen sobre la Justicia Social desde una perspectiva que toma en cuenta las tres dimensiones propuestas por Nancy Fraser (2008) de Redistribución, Reconocimiento y Representación/Participación. Para ello, se han elaborado el Cuestionario de Representaciones de Justicia Social para Estudiantes de Educación Secundaria (CRJSES) y el Cuestionario de Representaciones de Justicia Social para Profesores (CRJSP). El CRJSES consta de 30 preguntas en formato de dilemas, presentando 10 preguntas de cada una de las dimensiones de Justicia Social. El CRJSP tiene 39 preguntas, incluyendo 9 dilemas adicionales sobre temas relacionados con la Justicia Social en el ámbito educativo. En todas las preguntas se plantea un dilema con tres opciones de respuesta que plantean distintos grados de justicia social (alto, medio y bajo). Los instrumentos han seguido un doble proceso de validación: una validación de jueces expertos y un estudio piloto que ha sido aplicado a 130 profesores en formación. Los resultados indican que los dos instrumentos presentan una validez y fiabilidad adecuadas para evaluar las representaciones de Justicia Social de estudiantes de Educación Secundaria y docentes.
\end{abstract}

Descriptores: Justicia social; Representaciones sociales; Estudiantes; Profesorado; Educación secundaria.

This article describes the process of construction and validation of two instruments designed to evaluate the representations that students and teachers have about Social Justice from a perspective that takes into account the three dimensions proposed by Nancy Fraser (2008) of Redistribution, Recognition and Representation/Participation. To this end, the Social Justice Representations Questionnaire for Secondary Students (SJROSS) and the Social Justice Representations Questionnaire for Teachers (SJRQT) have been developed. The SJRQSS consists of 30 questions in a dilemma format, presenting 10 questions from each of the Social Justice dimensions. The SJRQT has 39 questions, including 9 additional dilemmas on issues related to Social Justice in education. Each question poses a dilemma with three response options which pose different degrees of social justice (high, medium and low). The instruments have followed a double validation process: a validation by expert judges and a pilot study that has been applied to 130 teachers in training. The results indicate that the two instruments have adequate validity and reliability to evaluate the social justice representations of secondary students and teachers.

Keywords: Social justice; Social representations; Students; Teachers; Secondary education.

*Contacto: vanesa.sainz@ufv.es

ISSN: 2254-3139

www.rinace.net/riejs/

revistas.uam.es/riejs
Recibido: $\quad 25$ de marzo 2020

$1^{\text {a }}$ Evaluación: 13 de junio 2020

$2^{\text {a }}$ Evaluación: 2 de julio 2020

Aceptado: 17 de julio 2020 


\section{Introducción}

El término de Justicia Social se ha utilizado de formas muy diferentes y con significados e interpretaciones muy distintas (Novak, 2000; Sandretto, 2008), por lo que podría decirse que en la actualidad existen concepciones plurales acerca de la justicia social (Gewirtz y Cribb, 2002). Para las ciencias sociales y especialmente para la educación, este concepto tiene una enorme relevancia, siendo necesario avanzar hacia una descripción más sistemática y elaborada del término respecto a sus distintos significados y usos en distintos contextos políticos y sociales (Jacott et al., 2019).

La noción comúnmente asumida de que todo el mundo entiende lo que queremos decir con el concepto de Justicia Social presupone partir de un consenso inexistente en la actualidad que ha llevado en muchas ocasiones a generar confusión y contradicciones sobre las situaciones de injusticia y desigualdad experimentadas por los diferentes grupos sociales y por las personas en las escuelas, y en la sociedad en general. Sin embargo, como expone Cuervo (2012), examinar el elemento subjetivo de Justicia Social que tienen las personas, puede hacer una contribución importante a la comprensión teórica del concepto y de cómo las injusticias sociales se experimentan y se perpetúan en los distintos entornos, especialmente en los más desfavorecidos.

Hasta la fecha, varios han sido los instrumentos que se han elaborado con la intención de evaluar asuntos relativos a la Justicia Social (Corning y Myers, 2002; Chen-Hayes, 2001; Ludlow, Enterline y Cochran-Smith, 2008; Miller et al., 2009; Murillo et al., 2014; Nilsson et al., 2011; Rasinski, 1987; Torres-Harding, Siers y Olson, 2012). Sin embargo, ninguna de estas escalas permite conocer las representaciones de Justicia Social de estudiantes y docentes desde la triple visión dimensional propuesta por Fraser (2008) de Redistribución, Reconocimiento y Representación.

La educación para la Justicia Social incluye estrategias pedagógicas y métodos de enseñanza, pero también implica lo que docentes y estudiantes creen y cómo piensan sobre la Justicia Social, así como los marcos a través de los cuales interpretan lo que sucede en las escuelas y en las clases, y cómo identifican y desafían las desigualdades e injusticias.

Fomentar cambios en la educación centrados en Justicia Social lleva tiempo y esfuerzo (Patterson, Doppen y Misco, 2012), y para conseguirlos es necesario identificar y considerar el sistema de creencias y representaciones que tienen los actores principales de la educación.

Por lo tanto, las representaciones o creencias sobre Justicia Social constituyen un paso previo para facilitar el compromiso de las y los estudiantes para tomar acción (Goodman, 2000; Miller et al., 2009; Torres-Harding, Siers y Olson, 2012). Por ello, es muy importante el desarrollo de instrumentos que permitan conocer las representaciones de Justicia Social que promueven una posición más activa, convirtiendo a estudiantes y docentes en agentes de cambio con intención de eliminar $-\mathrm{o}$ al menos reducir significativamente- las injusticias y desigualdades que se producen en la sociedad. 


\section{Revisión de la literatura}

\subsection{Concepto de justicia social}

En este estudio se asume el planteamiento de Justicia Social basado en las ideas de Rawls (1971) y Sen (2009) como Redistribución de bienes, servicios, recursos, capacidades y funcionamientos; sumado a las ideas de Fraser (2008), y su defensa del Reconocimiento (Taylor, 1996; Walzer, 1983; Young, 2000) y de la Representación o Participación (Avendaño, 2010; Pérez de la Fuente, 2011) como elementos constituyentes y diferenciados, así como complementarios. En este sentido lo reflejan también Murillo y Hernández (2011) y otros autores (Tikly y Barrett, 2011; Walker, 2006), que aplican la propuesta al ámbito educativo.

La triple visión dimensional del concepto de Justicia Social (las 3 Rs de la Justicia Social) fue propuesta inicialmente por Fraser (2008) en su libro Escalas de Justicia y plantea que para poder alcanzar la Justicia Social es necesario el desarrollo de tres principios o dimensiones: la Redistribución de recursos materiales, culturales, bienes primarios y capacidades; el Reconocimiento y respeto cultural de todas y cada una de las personas, otorgando valor, empoderamiento y celebridad a la diversidad; y la Representación o participación activa de todos los ciudadanos, especialmente en decisiones que afectan a sus propias vidas.

Hay que considerar también que a pesar de que en un primer momento pueda ser útil a efectos descriptivos la triple visión dimensional de Justicia Social; las Rs no pueden definirse por una sola dimensión conceptual, pues implican otras muchas cuestiones. Centrándonos en el ámbito educativo, la Redistribución no sólo tiene que ver con los recursos, sino también con las expectativas de los docentes; el Reconocimiento, está asociado con las diferentes capacidades, valores e identidades de estudiantes y profesores; y la Representación está influida a su vez por la lógica redistributiva y por el reconocimiento de los colectivos tradicionalmente excluidos y sus derechos, que determinan la participación democrática de estudiantes, docentes y en general de todos los miembros de la comunidad educativa.

Por ello, es necesario profundizar en esta íntima interrelación entre las tres dimensiones de Justicia Social, y en su propia coherencia interna. Está bien diferenciarlas conceptualmente, pero en la realidad y en la vida cotidiana aparecen fuertemente interrelacionadas con base a los diferentes niveles de desigualdades existentes y a los distintos contextos en los que se producen.

Además, la Justicia Social se platea como un proceso en desarrollo, dentro de un continuo que se desliza entre la opresión y la igualdad social. En este sentido, es posible, como sugiere Bonnycastle (2011), pensar en las acciones que promueven la Justicia Social articuladas en torno a un continuo que va desde las acciones que contribuyen a mantener o incluso aumentar las situaciones de desigualdad e injusticia, hasta el otro extremo, en el que se encuentran las acciones orientadas a eliminar (o reducir) las injusticias, y promover las libertades, las capacidades y el pleno desarrollo humano.

\subsection{Representaciones sociales y justicia social}

La noción de Representaciones Sociales ha sido ampliamente trabajada desde los trabajos de Moscovici (2001) que inició este campo de investigación asociado a la construcción social de la realidad. En este sentido, es destacable la recopilación de trabajos que se han 
hecho sobre este tema en "The Cambridge Handbook of Social Representations" (Sammut et al., 2015), un manual que tiene como objetivo avanzar en la teoría de las representaciones sociales a través de sus principales principios teóricos, metodológicos y aplicados.

Las representaciones sociales constituyen un conocimiento formado a partir de nuestras experiencias, informaciones, conocimientos y modelos de pensamiento que recibimos y nos transmiten a través de la educación, la comunicación social y las tradiciones sociales y culturales (Jodelet, 1993). Estas creencias representan opiniones y actitudes que se organizan y estructuran constituyendo un tipo particular de sistema cognitivo-social (Sepúlveda-Parra, 2010). En este sentido, las representaciones sociales constituyen un sistema organizado de creencias, con origen en las experiencias de las personas y especialmente desarrolladas en sus interacciones sociales (Remesal, 2011).

Además, estas representaciones sirven de guía para los comportamientos y las actitudes, y permiten justificarlas (Sepúlveda-Parra, Brunaud-Vega y Carreño González, 2016). Es decir, estas creencias o representaciones son muy influyentes en nuestro comportamiento y en los procesos de toma de decisiones al estar fuertemente constituidas e integradas en nuestra cognición (Patterson, Doppen y Misco, 2012; Wagner, 2015). Por lo tanto, al estudiar las representaciones sociales podemos predecir los comportamientos de los grupos e individuos respecto a las nociones que se analizan (Sammut, 2015).

Las representaciones en el ámbito de la Justicia Social son definidas por Reason y Davis (2005) como las creencias acerca de la consecución de los objetivos de Justicia Social. Siguiendo el planteamiento de que las representaciones son descritas como las disposiciones generales de implicación hacia un comportamiento, en lo relativo a la Justicia Social, supone la aceptación de que las concepciones y valores que tienen las personas en este ámbito, determinan en buena medida, sus actuaciones y su implicación por la Justicia Social. Hay varios estudios (Miller et al., 2009; Torres-Harding, Siers y Olson, 2012) que prueban y predicen los comportamientos y el compromiso hacia la Justicia Social a partir de los intereses, las actitudes y la autoeficacia en Justicia Social que muestran las personas. Ajzen (1991) presenta un modelo cognitivo-social que proporciona un marco útil para considerar que las actitudes, las intenciones, las creencias y los constructos relacionados predicen los comportamientos orientados hacia la Justicia Social.

Los estudios empíricos que evalúan las creencias y representaciones de las distintas poblaciones en este ámbito destacan por ser un indicador firme del compromiso por la defensa de la Justicia Social (Miller et al., 2009). Además, las personas que utilizan ideas más flexibles y se muestran más abiertas acerca de cómo promover la Justicia Social, son capaces de integrar con más éxito actividades de acción social para reducir las injusticas en su vida personal y profesional. En cambio, los que ven los esfuerzos relacionados con la Justicia Social como difíciles, desafiantes o abrumadores muestran una barrera para la acción social (Torres-Harding et al., 2014).

Las representaciones de Justicia Social corresponden con unas percepciones que se van construyendo a lo largo de la vida, reflejando en esta definición un desarrollo evolutivo del concepto, influido por los ambientes en los que se desarrollan las personas, entre los que destacan los contextos sociales, familiares y educativos (Jornet-Meliá, Sancho-Álvarez y Bakieva, 2015). Por lo tanto, podemos decir que las representaciones sociales es un concepto que se desarrolla a lo largo del tiempo y evoluciona con la experiencia de los individuos (Lahlou, 2015). 
Centrándonos en el ámbito educativo, las concepciones o representaciones de estudiantes y docentes son definidas como el marco de referencia que utilizan para interpretar sus experiencias vividas en los centros educativos y a través de las cuales interactúan en el aula (Pratt, 1992). Según describe Sepúlveda-Parra (2010), las representaciones de Justicia Social en los centros educativos están mediadas por el conjunto de interrelaciones que se producen entre los distintos agentes de la comunidad educativa, entre los que cabe destacar, estudiantes, familias, profesorado, personal de administración e incluso por el currículo.

Las representaciones de Justicia Social de estudiantes informan sobre el contexto social en el que están siendo formados $\mathrm{y}$, por tanto, de las experiencias que viven en la sociedad y en la escuela. Los estudiantes van construyendo una representación de Justicia Social a través de las experiencias y situaciones de su vida cotidiana, que van calificando como más o menos justas (Sepúlveda-Parra, Brunaud-Vega y Carreño González, 2016). Por lo tanto, estas representaciones sociales han sido generadas por las experiencias previas vividas, y son manifestadas a través de las acciones y juicios valorativos al señalar las situaciones y hechos escolares como justos o injustos.

\subsection{Desarrollo de escalas e instrumentos para evaluar la justicia social}

En el ámbito de la educación es indudable que la Justicia Social genera una amplia preocupación, por parte de teóricos, investigadores, e incluso del profesorado y toda la comunidad educativa en general. Sin embargo, son pocos los instrumentos que se han desarrollado hasta el momento para evaluar este concepto.

El instrumento más antiguo del que hay constancia es la Escala del Mundo Justo (Belief in a Just World-BJW) de Rubin y Peplau (1973, 1975). Esta Escala de 20 ítems está fundamentada en la creencia percibida del mundo justo basándose en la teoría de que las personas consiguen lo que merecen en la vida y, que generalmente la gente es responsable de su propia desgracia o fortuna, vinculando el destino de las personas con su mérito y esfuerzo.

Posteriormente, Dalbert, Montada y Schmitt (1987) proponen una adaptación de esta Escala de creencias en el mundo justo (General Belief in a Just World Scale) compuesta por seis ítems. Por otra parte, Lipkus (1991) hace una nueva adaptación de la Escala del Mundo Justo creada por Rubin y Peplau (1975) en una versión de siete ítems con el nombre Escala de Creencia Global en un Mundo Justo (Global Belief in a Just World Scale$G B J W$ ), siendo esta la más utilizada en los últimos estudios que se han realizado sobre este tema. En general, en los estudios que se han hecho (Ajzen, 1991; Barreiro, Etchezahar, y Prado-Gasco, 2014; Torres-Harding et al., 2014) se ha observado que la creencia en el mundo justo correlaciona negativamente con las medidas de Justicia Social.

Desde la disciplina psicológica, algunos investigadores han desarrollado escalas que examinan el grado en que los psicólogos se comprometen en comportamientos relacionados con la Justicia Social. Por ejemplo, Ritchhart (2002) desarrolló la Escala de Creencias de Activismo Social (Social Activism Beliefs Rating Scale-SABR) para medir el activismo y las actitudes de los psicólogos hacia la Justicia Social en sus roles profesionales. Por otra parte, Dean (2009) desarrolló la Escala de promoción de Justicia Social (Social Justice Advocacy Scale) para medir el grado en que los psicólogos se comprometen en acciones colaborativas, en el empoderamiento del cliente en el contexto de una relación terapéutica y en la promoción política y social. El problema de estas escalas 
es que están limitadas para el trabajo de la Justicia Social en el ámbito de la psicología y la asesoría, con dificultad de ser aplicadas a distintas poblaciones.

Otras escalas han sido desarrolladas para evaluar las percepciones de justicia en otros contextos y ámbitos específicos. Por ejemplo, Colquitt (2001) ha desarrollado una Escala de Justicia Organizacional (Organizational Justice Scale). Desde una perspectiva más amplia, Miller y colaboradores (2009), han desarrollado una Escala centrada en la evaluación de cuestiones sociales (The Social Issues Questionnaire) con el objetivo de entender el proceso cognitivo-social que utilizan los individuos cuando desarrollan acciones en el ámbito de la Justicia Social. Este cuestionario, aunque fue originalmente creado para predecir la elección de carrera, los intereses y el logro de metas, también se encarga de evaluar cómo las y los estudiantes podrían desarrollar intereses y compromisos por la Justicia Social.

En la investigación de Nilsson y otros (2011) también realizan la elaboración y evaluación de una Escala para medir la defensa y la promoción de cuestiones sociales (The Social Issues Advocacy Scale-SIAS). Este cuestionario evalúa las actitudes y los comportamientos de promoción hacia la Justicia Social en tres áreas (personal, profesional y legislativa) a través de cuatro factores: promoción política y social, confrontación de la discriminación, conciencia política, y conciencia en asuntos sociales.

Torres-Harding, Siers y Olson (2012) desarrollaron y evaluaron la Escala de Justicia Social (Social Justice Scale-SJS) para medir las actitudes, los valores, la autoeficacia percibida y las intenciones para comprometerse en Justicia Social en base a la concepción de los cuatro factores de la teoría de Ajzen (1991): actitudes, intenciones, creencias y comportamientos.

Otros investigadores han desarrollado también instrumentos para medir la justicia basándose en los principios de justicia distributiva y procedimental. Por ejemplo, Rasinski (1987) desarrolla una Escala (Proportionality Scale) para medir el grado en el que la gente utiliza principios de proporcionalidad (igualdad de oportunidades) o igualitarismo (igualdad de resultados) para promover el alcance de la Justicia Social.

Por otra parte, en relación a la dimensión de Representación de Justicia Social, Corning y Myers (2002) desarrollaron la Escala de Orientación Activista (Activism Orientation Scale) para evaluar el grado en que los individuos creen que tienen capacidad para influir en los procesos políticos y, su inclinación a comprometerse en comportamientos activistas. Sin embargo, activismo político es sólo un componente del trabajo por la Justicia Social vinculado con la dimensión de Participación o Representación.

Centrándonos en el ámbito educativo, entre los instrumentos de evaluación de la Justicia Social, está el Social Justice Advocacy Readiness Questionnaire (Chen-Hayes, 2001) que fue desarrollado con la intención de ayudar a los responsables de la educación a comprometerse en su propia autoevaluación, conciencia, nivel de compromiso y valores para la promoción de la Justicia Social con diversos grupos.

Por otra parte, en relación a los docentes, The Boston College Teachers for a New Era Evidence Team desarrolló la escala Lerning to Teach for Social Justice-Beliefs (LTSJ B) (Ludlow, Enterline, y Cochran-Smith, 2008) para medir las creencias del profesorado asociadas con el compromiso hacia la Justicia Social. Este instrumento evalúa las ideas que tienen los docentes sobre la redistribución de recursos, oportunidades y resultados de 
aprendizaje, y el reconocimiento de las tradiciones, los conocimientos y las fortalezas de los estudiantes.

Otros autores (Murillo et al., 2014) han elaborado La Escala de Actitudes hacia la Justicia Social en Educación (EAJSE), que consta de tres subescalas: Actitudes hacia la Justicia Social, Actitudes hacia la Justicia Social en Educación y Compromiso personal docente con la Justicia Social.

En el cuadro 1 se pueden observar las principales escalas e instrumentos que se han utilizado para evaluar aspectos relacionados con la Justicia Social, ordenados por fecha de elaboración, desde los más antiguos a los más recientes.

Cuadro 1. Escalas e instrumentos relacionados con la justicia social

\begin{tabular}{ll}
\hline \multicolumn{1}{c}{ AUTORAS/AUTORES (AÑO) } & \multicolumn{1}{c}{ NoMBRE DE LA ESCALA } \\
\hline Rubin y Peplau (1973, 1975) & Belief in a Just World (BJW) \\
Dalbert, Montada y Schmitt (1987) & General Belief in a Just World Scale \\
Rasinski (1987) & Proportionality Scale \\
Lipkus (1991) & Global Belief in a Just World Scale (GBJW) \\
Chen-Hayes (2001) & Social Justice Advocacy Readiness Questionnaire \\
Colquitt (2001) & Organizational Justice Scale \\
Ritchhart (2002) & Social Activism Beliefs Rating Scale (SABR) \\
Corning y Myers (2002) & Activism Orientation Scale \\
Dean (2009) & Social Justice Advocacy Scale \\
Ludlow, Enterline y Cochran-Smith & Learning to teach for Social Justice-Beliefs \\
(2008) & The Social Issues Questionnaire (SIQ) \\
Miller y otros (2009) & The Social Issues Advocacy Scale (SIAS) \\
Nilsson et al. (2011) & Social Justice Scale (SJS) \\
Torres-Harding, Siers y Olson (2012) & Escala de Actitudes hacia la Justicia Social en \\
Murillo y otros (2014) & Educación (EAJSE) \\
\hline
\end{tabular}

Fuente: Elaboración propia.

Tras la revisión de los instrumentos, se ha podido observar que ninguna de estas escalas evalúa las representaciones de Justicia Social desde la triple visión dimensional (Redistribución, Reconocimiento y Representación). Por esta razón, en este estudio se presenta la elaboración de dos instrumentos para evaluar las representaciones de justicia social que tienen el profesorado y los estudiantes de Educación Secundaria.

Cabe señalar que en este artículo solo presentamos el proceso de diseño y validación de los instrumentos, dejando fuera los resultados de los estudios realizados sobre las representaciones de justicia social que tienen estudiantes de educación secundaria y profesorado en distintas regiones de España (Sainz, 2017; Sainz y Jacott, 2020).

\section{Método}

Los instrumentos desarrollados presentan diseño y validación inédita $\mathrm{y}$, han sido elaborados por un grupo interdisciplinar de expertas y expertos en Justicia Social del Grupo de Investigación Cambio Educativo para la Justicia Social (GICE) de la Universidad Autónoma de Madrid. Los miembros del grupo de expertos provienen de diversas disciplinas (educación, psicología, historia, pedagogía, sociología y antropología), lo que ha hecho posible enriquecer los instrumentos desde distintas perspectivas y orientaciones teóricas. 
Para la elaboración de los cuestionarios se han realizado un total de seis reuniones con las expertas y expertos en Justicia Social durante el curso 2015-2016, con una duración de entre tres y cuatro horas cada una. Esta labor fue complementada y enriquecida con el trabajo externo, individual y autónomo de cada uno de ellos.

Cada persona experta se encargaba de aquellas cuestiones que eran específicas o más afines a su disciplina teórica y a su campo de actuación profesional, planteando preguntas en formato de dilemas. Tras la elaboración de las preguntas, se pasó a la fase de contrabalanceo, que consistía en clasificarlas en función de la dimensión a la que pertenecían (Redistribución, Reconocimiento o Representación), con el fin de asegurarnos que el cuestionario contenía el mismo número de preguntas de cada una de las dimensiones.

La distribución de las preguntas por dimensiones de Justicia Social no fue una tarea sencilla, pues los dilemas planteados pueden hacer referencia a dimensiones que comparten planteamientos intrínsecamente relacionados y aunque en todas las preguntas hay una dimensión predominante, algunas implican asuntos de más de una dimensión. Finalmente, tras la elaboración y selección de las preguntas, se llevó a cabo un proceso de validación de los instrumentos, para analizar su validez y fiabilidad. En la figura 1 se muestra una síntesis esquematizada de las fases del proceso recursivo que se han seguido para la elaboración de los cuestionarios.

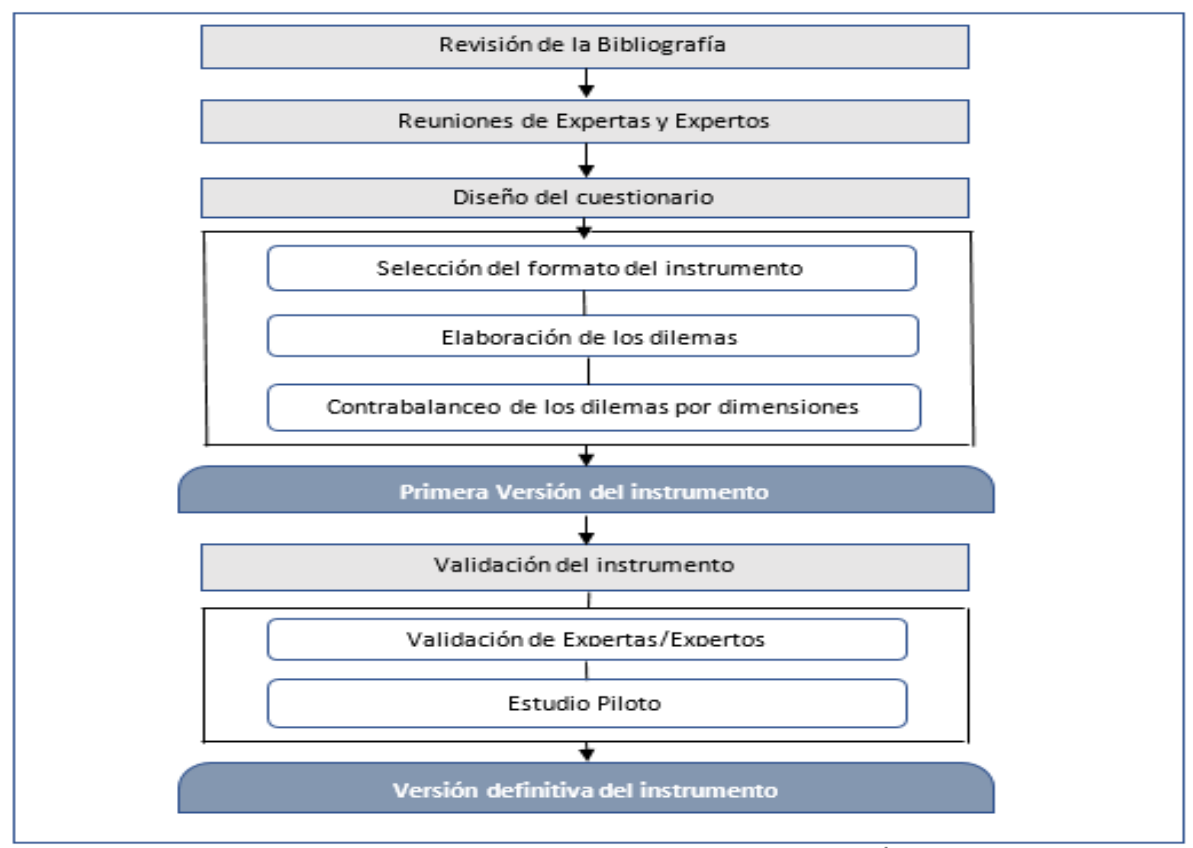

Figura 1. Esquema del proceso de elaboración de los cuestionarios de representaciones de justicia social

Fuente: Elaboración propia.

Partiendo del modelo teórico, que plantea una visión tridimensional de la Justicia Social, se ha elaborado el Cuestionario de Representaciones de Justicia Social para Estudiantes de Educación Secundaria (CRJSES) y el Cuestionario de Representaciones de Justicia Social para Profesores (CRJSP) (ver Anexo). Estos instrumentos permiten analizar los patrones de pensamiento de estudiantes y profesores en torno a las tres grandes dimensiones teóricas o componentes de la Justicia Social (Redistribución, Reconocimiento 
y Representación), así como del constructo global de Justicia Social, integrado por estos tres componentes previos.

El CRJSES consta de 30 preguntas, 10 de cada una de las dimensiones de Justicia Social (10 de Redistribución, 10 de Reconocimiento y 10 de Representación). El CRJSP consta de 39 preguntas, 13 de cada dimensión (13 de Redistribución, 13 de Reconocimiento y 13 de Representación). Esta versión para profesorado incluye las 30 preguntas del CRJSES y 9 preguntas adicionales sobre temas de índole educativa, específicamente diseñadas para ser contestadas por personas expertas en educación.

Las tres dimensiones que integran el constructo teórico de Justicia Social (Redistribución, Reconocimiento y Representación) incluyen subcategorías más específicas, entre las que se incluyen: distribución de bienes primarios, recursos y servicios, prejuicio, discriminación, racismo, sexismo, homofobia, participación, ciudadanía, globalización, acceso a las TICs, políticas fiscales de redistribución social (impuestos), diversidad familiar, relaciones Estado-ONG's, políticas educativas, democracia, globalización, migración, etc. Como se puede observar, los cuestionarios recogen una variedad muy amplia de problemáticas sociales que implican cuestiones de Justicia Social de diversos ámbitos, como la economía, la educación, la democracia y la diversidad, entre otros.

En el cuadro 2 se puede observar el foco de contenido y la clasificación en función de las tres dimensiones de Justicia Social (Redistribución, Reconocimiento y Representación) de las 30 preguntas del CRJSES -que también corresponden con la ordenación de las primeras 30 preguntas del CRJSP-, así como de las nueve preguntas adicionales que se han incluido en el CRJSP sobre cuestiones de justicia social en el ámbito de la educación.

En cuanto al planteamiento y discurso de las preguntas, todas han sido elaboradas con una formulación de dilemas hipotéticos con tres alternativas de respuesta, es decir, trilemas en sentido estricto. En cada uno de los dilemas, se plantea una narración breve sobre una situación hipotética, pero susceptible de ser evaluada reflexionando sobre las problemáticas sociales que se plantean en la actualidad.

Las preguntas han sido formuladas como polinómicas cerradas de respuesta única con tres opciones de respuesta, que han sido elaboradas como planteamientos cerrados y excluyentes. Las tres alternativas están graduadas en función de un continuo de Justicia Social (Bonnycastle, 2011), pudiendo diferenciar para cada dilema tres tipos de respuesta:

- Alternativa de Justicia Social alta: se plantea como la opción más próxima a la Justicia Social.

- Alternativa de Justicia Social media: se sitúa en una posición intermedia en el continuo de Justicia Social.

- Alternativa de Justa Social baja: se plantea como la opción más alejada a la Justicia Social. 
Cuadro 2. Distribución de los dilemas por dimensión y contenido focal

\begin{tabular}{|c|c|}
\hline $\mathbf{N}^{\circ}$ DE DILEMA & $\begin{array}{l}\text { TIPO DE DILEMA (FOCO) } \\
\end{array}$ \\
\hline 1 & Reconocimiento (Idioma) \\
\hline 2 & Redistribución (Alumnos con Necesidades) \\
\hline 3 & Reconocimiento (Acceso TIC) \\
\hline 4 & Representación (Elección Delegado) \\
\hline 5 & Redistribución (Dificultades Aprendizaje) \\
\hline 6 & Representación (Comisión Escolar) \\
\hline 7 & Reconocimiento (Mujeres) \\
\hline 8 & Redistribución (Países Pobres) \\
\hline 9 & Representación (Voto Elecciones Generales) \\
\hline 10 & Reconocimiento (Acoso Escolar) \\
\hline 11 & Redistribución (Campañas Prevención) \\
\hline 12 & Representación (Políticos) \\
\hline 13 & Redistribución (Discapacidad Laboral) \\
\hline 14 & Representación (Alumnos Escasa Participación) \\
\hline 15 & Reconocimiento (Religión/Hiyab) \\
\hline 16 & Redistribución (Ayudas Países Pobres) \\
\hline 17 & Representación (Consultas Ciudadanas) \\
\hline 18 & Reconocimiento (Identidad Cultural) \\
\hline 19 & Redistribución (Becas Escolares) \\
\hline 20 & Representación (Gobierno Democrático) \\
\hline 21 & Reconocimiento (Familia) \\
\hline 22 & Representación (Lenguas Cooficiales) \\
\hline 23 & Reconocimiento (Hijos Parejas Homosexuales) \\
\hline 24 & Redistribución (Excursión) \\
\hline 25 & Representación (Jóvenes Política) \\
\hline 26 & Reconocimiento (Matrimonio Homosexual) \\
\hline 27 & Redistribución (Trabajo Infantil) \\
\hline 28 & Reconocimiento (Censura Internet) \\
\hline 29 & Redistribución (Impuestos) \\
\hline 30 & Representación (Justicia Universal) \\
\hline 31 & Justicia Social en Educación (Actividades Extraescolares) \\
\hline 32 & Justicia Social en Educación (Obligatoriedad Enseñanza) \\
\hline 33 & Justicia Social en Educación (Comprensividad/Diversificación) \\
\hline 34 & Justicia Social en Educación (Financiación Centros Educativos) \\
\hline 35 & Justicia Social en Educación (Educación Segregada Por Género) \\
\hline 36 & Justicia Social en Educación (Adaptaciones Curriculares) \\
\hline 37 & Justicia Social en Educación (Material Escolar) \\
\hline 38 & Justicia Social en Educación (Bachillerato Excelencia) \\
\hline 39 & Justicia Social en Educación (Abuso pareja) \\
\hline
\end{tabular}

Fuente: Elaboración propia.

En la figura 2 se muestra la distribución gráfica de las alternativas sobre el continuo de Justicia Social.

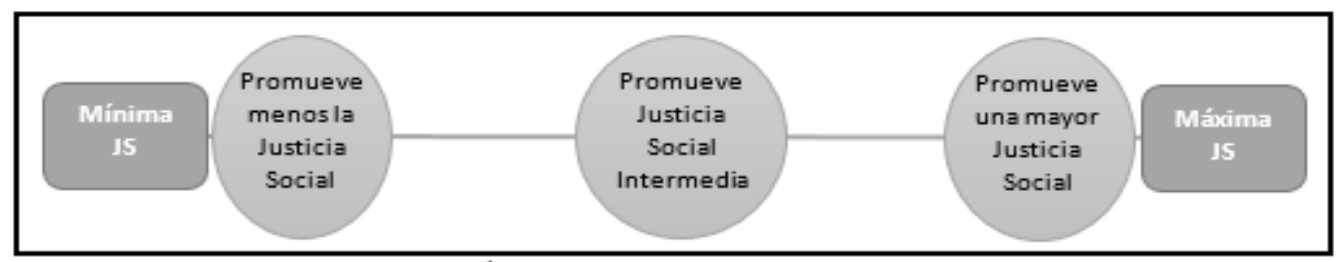

Figura 2. Distribución de las alternativas en el continuo de justicia social Fuente: Elaboración propia. 
Para poder observar con mayor concreción y detalle la estructura y composición de las preguntas y de sus alternativas, se presenta un ejemplo de dilema de cada una de las dimensiones del cuestionario. En la figura 3 se puede observar un ejemplo de la dimensión de Redistribución.

Andrea tiene 8 años y va siempre al colegio en silla de ruedas. El patio es de arena y su familia solicita que una parte del mismo sea cubierto con material liso y firme, para que sea más fácil moverse y jugar en el patio con otros niños y niñas. La obra es cara. ¿Qué opción apoyarías tú?:

A) Gastar todo el dinero necesario e iniciar las obras en el menor tiempo posible, para que Andrea pueda jugar como los demás.

B) Arreglar al menos la mitad del patio para que pueda jugar.

C) Gastar más en obras que beneficien a la mayoría y buscar una solución alternativa para los casos particulares como éste.

Figura 3. Ejemplo de dilema de la dimensión de redistribución Fuente: Elaboración propia.

En este dilema de la dimensión de Redistribución, la alternativa A representa la opción con mayor grado de promoción de Justicia Social, la alternativa C plantea la respuesta valorada con el grado de Justicia Social más bajo y la opción B, muestra un grado intermedio en Justicia Social. En la figura 4 se presenta uno de los dilemas de la dimensión de Reconocimiento.

Pablo es un estudiante de $2 \circ$ de ESO al que un grupo de su clase molesta y acosa continuamente. Santiago sabe lo que están haciendo sus amigos y amigas y quiere pararlo. ¿Qué es lo que debería hacer?:
A) Decirles que no pueden hacerle eso a Pablo y, si no le hacen caso, pedir ayuda a un adulto.
B) No intervenir en las disputas, para no perder a sus amigas y amigos.
C) Hablar con Pablo para ayudarle a evitar y/o afrontar esas situaciones.

Figura 4. Ejemplo de dilema de la dimensión de reconocimiento Fuente: Elaboración propia.

En este caso, la alternativa valorada con mayor grado de Justicia Social es la C, seguida por la respuesta A que indica un grado de Justicia Social intermedio, y la opción B se plantea como contraria a la promoción de la Justicia Social.

Por último, en la figura 5 se puede ver un ejemplo de dilema de la dimensión de Representación.

En las elecciones generales de cualquier país deberian tener derecho al voto:

A) Solamente las ciudadanas y ciudadanos que han nacido en ese país.

B) Todas los ciudadanos y ciudadanas que tengan la nacionalidad, hayan nacido o no en ese país.

C) Todos los ciudadanos y ciudadanas que vivan en ese país.

Figura 5. Ejemplo de dilema de la dimensión de representación Fuente: Elaboración propia.

En este dilema, la alternativa C plantea el mayor grado de Justicia Social, la respuesta A tiene un planteamiento contrario a la Justicia Social y la opción B presenta un grado de Justicia Social intermedio. 
Como se puede observar en los ejemplos presentados, aunque las respuestas exigen una elección disyuntiva, seleccionando sólo una de las alternativas y descartando las restantes, las soluciones planteadas no producen una respuesta inmediata, pues por su formulación de dilemas, precisan de una reflexión previa para poder ser contestadas.

En los cuestionarios, además de las preguntas específicas para el análisis de las dimensiones de Justicia Social, también se plantearon preguntas de carácter sociodemográfico (edad, género, curso académico, lugar de nacimiento y nacionalidad) con la finalidad de clasificar la muestra y hacer los análisis en función de estos criterios.

\section{Escalas y subescalas de justicia social}

Para analizar las representaciones que tienen estudiantes y profesores sobre Justicia Social y poder comparar sus respuestas, se ha incluido el mismo número de dilemas en cada una de las dimensiones. De este modo, se han obtenido tres Subescalas específicas (Subescala de Redistribución, Subescala de Reconocimiento y Subescala de Representación) y una Escala Global de Justicia Social constituida por las 30 preguntas que forman el CRJSES.

Además, en el CRJSP, dirigido a profesores en ejercicio y docentes en formación, se ha obtenido una Escala de Justicia Social en Educación, formada por los nueve dilemas adicionales que se han añadido a dicho cuestionario.

En la figura 6 se representa un esquema de las Escalas y Subescalas de Justicia Social que se han empleado para el análisis de los cuestionarios.

Los resultados de las Escalas y Subescalas de Justicia Social se han obtenido sumando las puntuaciones de las preguntas vinculadas con cada una de las dimensiones y escalas. Posteriormente, se han transformado estas puntuaciones a una Escala de 0 a 100 para facilitar su análisis e interpretación.

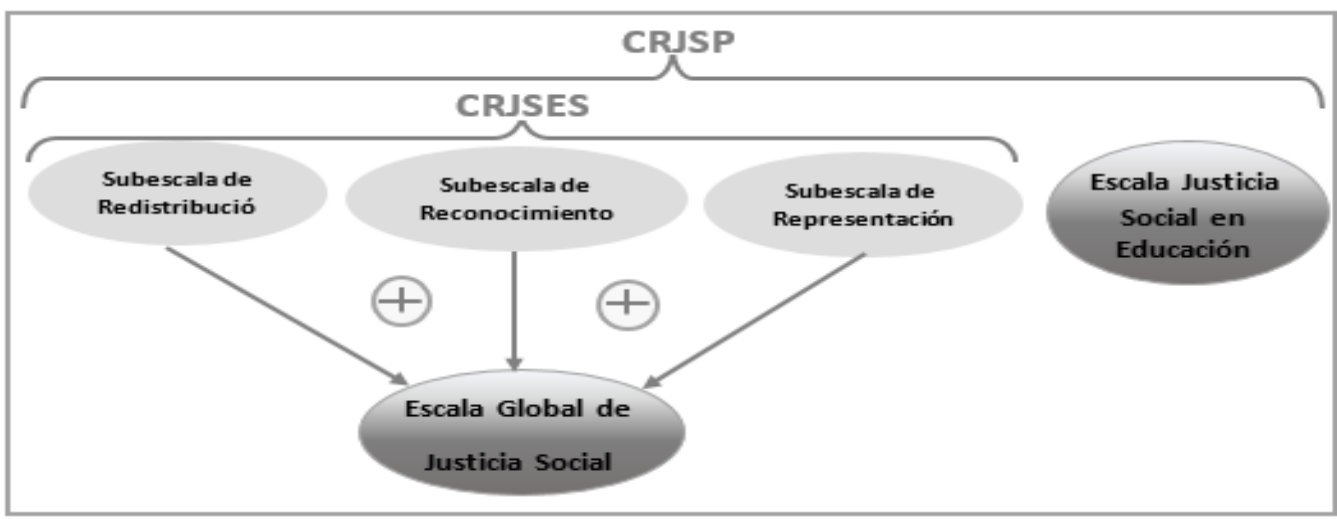

Figura 6. Esquema subescalas y escalas de justicia social Fuente: Elaboración propia.

\section{Validación de los cuestionarios}

Los cuestionarios han sido sometidos a un doble proceso de validación: validación de expertos y prueba piloto. A través del juicio de expertos se ha analizado la validez de contenido y de constructo de los instrumentos. Por otra parte, el estudio piloto nos ha permitido hacer un estudio de su fiabilidad. 


\subsection{Validación de expertos}

Está demostrado que la revisión de ítems por jueces es clave para demostrar la validez de constructo teórico y la validez de contenido (Cronbach, 1971).

El estudio de validez de los instrumentos se ha llevado a cabo por trece expertos en Justicia Social con una amplia experiencia en educación y conocedores del marco subyacente de investigación en el cual se ha desarrollado el diseño y la elaboración de los cuestionarios.

\subsubsection{Validez de contenido}

Los jueces expertos en Justicia Social han evaluado que el contenido de los dilemas fuera pertinente y adecuado para evaluar las representaciones de estudiantes y profesores sobre Justicia Social. Además, han valorado el grado de Justicia Social que representa cada una de las alternativas de todos los dilemas a través de una escala Likert graduada del 1 al 9, de menor a mayor Justicia Social.

En la figura 7 se muestra un ejemplo del formato de pregunta que se ha presentado a los expertos en Justicia Social.

Tras recopilar las respuestas de los expertos, se ha obtenido una puntuación media del grado de Justicia Social que representa cada una de las alternativas propuestas para todos los dilemas.

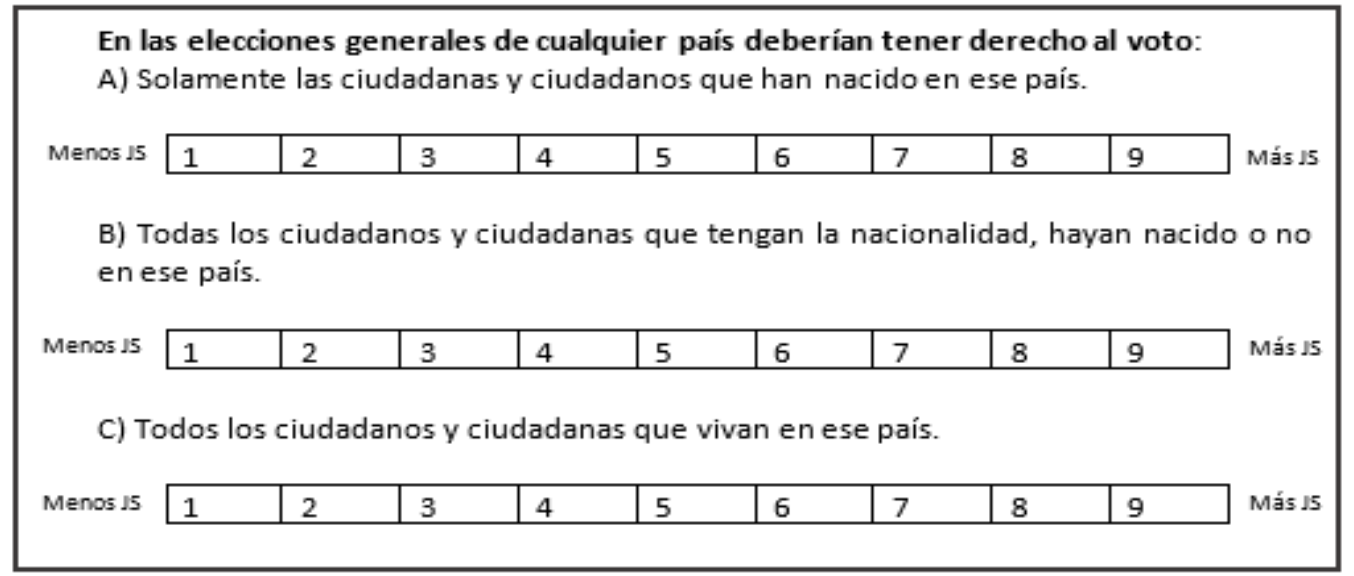

Figura 7. Ejemplo de dilema del instrumento para expertos Fuente: Elaboración propia.

\subsubsection{Validación de constructo}

Los jueces expertos en Justicia Social también han evaluado la validez de constructo de los instrumentos, determinando cuál de las dimensiones de Justicia Social (Redistribución, Reconocimiento y Representación) tiene mayor peso en cada uno de los dilemas.

Con la validez de constructo de los instrumentos se ha pretendido demostrar que existe un consenso intersubjetivo de jueces expertos en Justicia Social que garantiza la bondad de ajuste en las Escalas y Subescalas desde el marco conceptual propuesto para evaluar las Representaciones de estudiantes y docentes. La metodología del juicio de expertos utilizada en la validación del constructo teórico parte del modelo de Gable y Wolf (1993) que ha sido ampliamente revisado y contrastado (McCoach, Gable y Madura, 2013).

\subsection{Estudio piloto}


La segunda fase de validación del instrumento consistió en una aplicación experimental mediante una prueba piloto. Para ello, se aplicó el CRJSP a una muestra de 130 estudiantes del Master de Formación de Profesorado de Educación Secundaria Obligatoria y Bachillerato (MESOB) de la Universidad Autónoma de Madrid de diversas especialidades (Matemáticas, Física y Química, Dibujo, Geografía e Historia, Lengua y Literatura, Música, Biología y Geología).

Todos los participantes respondieron a la versión del cuestionario de 39 preguntas diseñada para el profesorado. Esto nos ha permitido verificar tanto las 30 preguntas comunes en el CRJSES y CRJSP, como las 9 preguntas adicionales añadidas al cuestionario de docentes.

\subsubsection{Fiabilidad}

Para calcular la fiabilidad de la prueba hemos obtenido el coeficiente alfa de Cronbach que nos indica la precisión con la que los ítems del cuestionario miden el concepto o ideas que tienen los participantes sobre temas de Justicia Social.

El valor obtenido de este índice de fiabilidad es de $\alpha=0,74$, lo que nos lleva a concluir que son instrumentos adecuados para evaluar las representaciones de Justicia Social de estudiantes y profesores. Los cuestionarios presentan una fiabilidad aceptable siguiendo el criterio general de George y Mallory (2003) y definido por otros autores (Kaplan y Saccuzzo, 2009) como un valor adecuado para considerar que el instrumento elaborado presenta coherencia y consistencia interna entre los elementos que lo integran.

Tras realizar los cálculos de fiabilidad de los instrumentos, se ha observado que el valor más elevado se obtiene cuando integramos todos los dilemas, pues la fiabilidad de la prueba no mejora al excluir ninguna de las preguntas del cuestionario.

Realizando el análisis de la fiabilidad por dimensiones, observamos que los niveles de consistencia interna descienden, obteniendo un valor para el coeficiente alfa de Cronbach de $\alpha=0,475$ en Redistribución, $\alpha=0,559$ en Reconocimiento y $\alpha=0,389$ en Representación.

Tras obtener estos valores de fiabilidad, podemos afirmar que los dilemas que integran el instrumento son más representativos de una dimensión global de Justicia Social que de las dimensiones específicas; confirmando que las tres dimensiones teóricas (Redistribución, Reconocimiento, Representación) que integran el constructo de Justicia Social comparten muchos de sus planteamientos.

Gracias a la colaboración de los expertos y a la aplicación del estudio piloto, hemos podido desarrollar una mejor redacción de las preguntas y una versión más perfeccionada de los instrumentos. En este proceso se recogieron todas las sugerencias y propuestas de mejora y se realizaron cambios en varias de las preguntas y alternativas. En concreto, se han realizado cambios en los dilemas 4, 6, 10, 12, 14, 16 y 23. Todas las recomendaciones recibidas se analizaron con detalle y rigurosidad, y sin duda, han beneficiado a la versión final, aunque no definitiva, de los instrumentos.

\subsubsection{Correlación}

Para estimar la efectividad discriminativa de los cuestionarios y poder determinar si los dilemas permiten diferenciar a los participantes que presentan diferentes grados en sus representaciones de Justicia Social se ha utilizado la correlación ítem-test. Este índice de 
discriminación se ha calculado a través de la correlación de Pearson de cada ítem respecto a todas las Escalas y Subescalas evaluadas. Estos análisis permiten evaluar la capacidad discriminativa de los instrumentos y el grado de asociación entre los dilemas y las distintas Escalas y Subescalas de Justicia Social.

En el cuadro 3 se presentan los valores de correlación de Pearson de los 39 dilemas respecto a las Escalas y Subescalas evaluadas y respecto a la puntuación global del cuestionario.

Cuadro 3. Correlaciones de Pearson dilema-dimensión

\begin{tabular}{|c|c|c|c|c|c|}
\hline Pregunta & $\begin{array}{l}\text { REDISTRIBU } \\
\text {-CIÓN }\end{array}$ & $\begin{array}{l}\text { RECONOCI- } \\
\text { MIENTO }\end{array}$ & $\begin{array}{l}\text { REPRESEN- } \\
\text { TACIÓN }\end{array}$ & $\begin{array}{c}\text { JS } \\
\text { EDUCACIÓN }\end{array}$ & $\begin{array}{c}\text { JS } \\
\text { ToTA } \\
\text { L } \\
\end{array}$ \\
\hline \multicolumn{6}{|l|}{ Redistribución } \\
\hline Dilema 2: Alumnos con necesidades & $0,465^{* *}$ & $0,106^{* *}$ & $0,151^{* *}$ & $0,141^{* * *}$ & $0,318^{* * *}$ \\
\hline Dilema 5: Dificultades aprendizaje & $0,322^{* *}$ & $0,145^{* *}$ & $0,148^{* *}$ & $0,110^{* * *}$ & $0,272^{* *}$ \\
\hline Dilema 8: Países pobres & $0,330^{* * *}$ & $0,127^{* * *}$ & $0,214^{* *}$ & $0,101^{* *}$ & $0,297^{* * *}$ \\
\hline Dilema 11: Campañas prevención & $0,273^{* *}$ & $0,116^{* * *}$ & $0,102^{* *}$ & $-0,031$ & $0,217^{* *}$ \\
\hline Dilema 13: Discapacidad laboral & $0,353^{* *}$ & $0,087^{* * *}$ & $0,116^{* *}$ & 0,006 & $0,245^{* * *}$ \\
\hline Dilema 16: Ayudas países pobres & $0,394^{* *}$ & $0,120^{* *}$ & $0,138^{* *}$ & 0,018 & $0,288^{* *}$ \\
\hline Dilema 19: Becas escolares & $0,305^{* *}$ & $0,137^{* *}$ & $0,180^{* *}$ & $0,158^{* *}$ & $0,275^{* *}$ \\
\hline Dilema 24: Excursión & $0,544^{* * *}$ & $0,108^{* *}$ & $0,128^{* *}$ & 0,059 & $0,343^{* *}$ \\
\hline Dilema 27: Trabajo infantil & $0,393^{* *}$ & $0,130^{* *}$ & $0,131^{* *}$ & $0,087^{* *}$ & $0,289^{* * *}$ \\
\hline Dilema 29: Impuestos & $0,456^{* *}$ & $0,108^{* *}$ & $0,095^{* * *}$ & 0,054 & $290^{* * *}$ \\
\hline \multicolumn{6}{|c|}{ Reconocimiento } \\
\hline Dilema 1: Idioma & $0,116^{* *}$ & $0,491^{* *}$ & $0,169^{* *}$ & $0,161^{* * *}$ & $0,351^{* * *}$ \\
\hline Dilema 3: Acceso TICS & $0,089^{* *}$ & $0,234^{* * *}$ & 0,019 & $-0,076^{*}$ & $0,155^{* *}$ \\
\hline Dilema 7: Mujeres & $0,220^{* * *}$ & $0,331^{* * *}$ & $0,129^{* *}$ & $0,174^{* *}$ & $0,305^{* * *}$ \\
\hline Dilema 10: Acoso escolar & $-0,097^{* * *}$ & $0,127^{* *}$ & $-0,017$ & $-0,045$ & 0,008 \\
\hline Dilema 15: Religión/Hiyab & $0,074^{*}$ & $0,420^{* * *}$ & $0,211^{* * *}$ & $0,191^{* *}$ & $0,319^{* * *}$ \\
\hline Dilema 18: Identidad cultural & $0,146^{* *}$ & $0,411^{* *}$ & $0,121^{* *}$ & $0,130^{* *}$ & $0,306^{* *}$ \\
\hline Dilema 21: Familia & $0,128^{* *}$ & $0,539^{* *}$ & $0,246^{* *}$ & $0,157^{* *}$ & $0,413^{* *}$ \\
\hline $\begin{array}{l}\text { Dilema 23: Hijos parejas } \\
\text { homosexuales }\end{array}$ & $0,109^{* *}$ & $0,555^{* *}$ & $0,225^{* *}$ & $0,213^{* *}$ & $0,403^{* *}$ \\
\hline Dilema 26: Matrimonio homosexual & $0,203^{* *}$ & $0,564^{* * *}$ & $0,248^{* *}$ & $0,238^{* * *}$ & $0,457^{* * *}$ \\
\hline Dilema 28: Censura internet & $0,196^{* *}$ & $0,455^{* *}$ & $0,161^{* *}$ & 0,056 & $0,366^{* *}$ \\
\hline \multicolumn{6}{|c|}{ Representación } \\
\hline Dilema 4: Elección delegado & $0,194^{* *}$ & $0,096^{* *}$ & $0,333^{\text {** }}$ & 0,046 & $0,277^{* * *}$ \\
\hline Dilema 6: Comisión escolar & $0,156^{* * *}$ & $0,206^{* * *}$ & $0,368^{* * *}$ & $0,153^{* *}$ & $0,326^{* * *}$ \\
\hline Dilema 9: Voto elecciones generales & $0,159^{* * *}$ & $0,225^{* *}$ & $0,462^{* *}$ & $0,143^{* * *}$ & $0,378^{* *}$ \\
\hline Dilema 12: Políticos & $0,127^{* * *}$ & $0,131^{* *}$ & $0,411^{* *}$ & $0,148^{* *}$ & $0,298^{* * *}$ \\
\hline Dilema 14: Alum. escasa participación & $0,197^{* *}$ & $0,152^{* *}$ & $0,478^{* *}$ & $0,104^{* *}$ & $0,368^{* *}$ \\
\hline Dilema 17: Consultas ciudadanas & $0,078^{*}$ & $0,156^{* *}$ & $0,417^{* *}$ & $0,109^{* *}$ & $0,291^{* *}$ \\
\hline Dilema 20: Gobierno democrático & $0,107^{* *}$ & $0,132^{* *}$ & $0,295^{* *}$ & $-0,025$ & $0,238^{* * *}$ \\
\hline Dilema 22: Lenguas cooficiales & $0,136^{* *}$ & $0,144^{* * *}$ & $0,290^{* * *}$ & $0,113^{* *}$ & $0,254^{* *}$ \\
\hline Dilema 25: Jóvenes política & $-0,013$ & $-0,022$ & $0,198^{* * *}$ & $-0,096^{* *}$ & $0,072^{*}$ \\
\hline Dilema 30: Justicia universal & $0,121^{* *}$ & $0,140^{* * *}$ & $0,385^{* *}$ & $0,173^{* *}$ & $0,288^{* *}$ \\
\hline \multicolumn{6}{|c|}{ Justicia Social en Educación } \\
\hline Dilema 31: Actividades extraescolares & 0,001 & $0,126^{* *}$ & $0,125^{* *}$ & $0,385^{* * *}$ & $0,114^{* *}$ \\
\hline Dilema 32: Obligatoriedad enseñanza & 0,057 & $0,111^{* * *}$ & $0,122^{* * *}$ & $0,436^{* *}$ & $0,130^{* *}$ \\
\hline $\begin{array}{l}\text { Dilema 33: Comprensividad } \\
\text { /diversificación }\end{array}$ & 0,009 & $-0,006$ & 0,017 & $0,286^{* *}$ & 0,009 \\
\hline Dilema 34: Financiación centros eds. & 0,046 & 0,053 & 0,008 & $0,287^{* *}$ & 0,048 \\
\hline Dilema 35: Ed. segregada género & $0,103^{*}$ & $0,151^{* *}$ & 0,063 & $0,312^{* *}$ & $0,142^{* *}$ \\
\hline Dilema 36: Adaptaciones curriculares & $0,083^{* *}$ & $0,093^{* *}$ & $0,109^{* *}$ & $0,481^{* *}$ & $0,127^{* * *}$ \\
\hline Dilema 37: Material escolar & $-0,071^{*}$ & 0,008 & 0,017 & $0,219^{* *}$ & $-0,020$ \\
\hline Dilema 38: Bachillerato excelencia & $0,198^{* * *}$ & $0,269^{* * *}$ & $0,200^{* *}$ & $0,550^{* *}$ & $0,299^{* * *}$ \\
\hline Dilema 39: Abuso pareja & $0,105^{* *}$ & $0,129^{* * *}$ & $0,133^{* * *}$ & $0,366^{* * *}$ & $0,164^{* *}$ \\
\hline
\end{tabular}

Nota: **La correlación es significativa al nivel 0,01. * La correlación es significativa al nivel 0,05.

Fuente: Elaboración propia.

Los resultados del cuadro 3 muestran que las puntuaciones de correlación más altas corresponden con las dimensiones que evalúan, presentando de este modo una correlación lineal positiva y significativa $(\mathrm{p}<0,01)$ con los niveles más altos de correlación sobre las Escalas y Subescalas que los integran. Estos resultados nos indican que, aunque muchos de los dilemas son multidimensionales, pues se ven implicados en más de una dimensión, 
tras valorar sus índices de correlación observamos que los valores más altos y significativos de cada uno de ellos, corresponden con las Subescalas que los integran.

Cuadro 4. Correlaciones de Pearson entre las subescalas de justicia social

\begin{tabular}{|c|c|c|c|c|c|c|}
\hline & & $\begin{array}{c}\text { REDISTRIBUCIÓ } \\
\mathbf{N}\end{array}$ & $\begin{array}{c}\text { RECONOCIMIENT } \\
\text { o }\end{array}$ & $\begin{array}{c}\text { REPRESENTACIÓ } \\
\mathbf{N}\end{array}$ & $\begin{array}{c}\text { JS } \\
\text { EDUCACIÓ } \\
\mathbf{N} \\
\end{array}$ & $\begin{array}{c}\text { JS } \\
\text { ToTA } \\
\text { L } \\
\end{array}$ \\
\hline \multirow[t]{2}{*}{ Redistribución } & $\begin{array}{l}\text { Pearso } \\
\mathrm{n}\end{array}$ & 1 & 0,317 & 0,346 & 0,175 & 0,728 \\
\hline & Sig. & & $0, \mathrm{OOO}^{* * *}$ & $0, \mathrm{OOO}^{* *}$ & $0, \mathrm{OOO}^{* * *}$ & $0,000^{* *}$ \\
\hline \multirow{2}{*}{$\begin{array}{l}\text { Reconocimient } \\
\mathrm{o}\end{array}$} & $\begin{array}{l}\text { Pearso } \\
\mathrm{n}\end{array}$ & & 1 & 0,404 & 0,289 & 0,751 \\
\hline & Sig. & & & $0,000^{* * *}$ & $0,000^{* *}$ & $0, \mathrm{OOO}^{* * *}$ \\
\hline \multirow{2}{*}{ Representación } & $\begin{array}{l}\text { Pearso } \\
\mathrm{n}\end{array}$ & & & 1 & 0,247 & 0,765 \\
\hline & Sig. & & & & $0,000^{* *}$ & $0,000^{* *}$ \\
\hline \multirow[t]{2}{*}{ JS Educación } & $\begin{array}{l}\text { Pearso } \\
\mathrm{n}\end{array}$ & & & & 1 & 0,319 \\
\hline & Sig. & & & & & $0,000^{* * *}$ \\
\hline
\end{tabular}

Nota: ** La correlación es significativa al nivel 0,01.

Fuente: Elaboración propia.

Al analizar las correlaciones entre las Escalas y Subescalas de Justicia Social, se puede observar en el cuadro 4 que existe una relación muy alta y significativa entre todas ellas $(\mathrm{p}<, \mathrm{OO} 1)$, confirmando que todas estas medidas de Justicia Social están muy relacionadas.

\section{Conclusiones}

Con la elaboración del CRJSES y del CRJSP, en este estudio se propone que las representaciones de estudiantes y docentes sobre Justicia Social constituyen un elemento que se puede medir y evaluar, presentando un interés especial para esta investigación su aplicación en el ámbito educativo.

Apoyándonos en lo que afirman algunos teóricos (Bonnycastle, 2011) acerca del concepto de Justicia Social y en otras escalas relacionadas (Enterline et al., 2008; Ludlow, Enterline, y Cochran-Smith, 2008; Patterson, Doppen y Misco, 2012), desde esta investigación se ha asumido que las representaciones que tienen estudiantes y docentes sobre Justicia Social pueden situarse a lo largo de un continuo, que va desde niveles relativamente débiles, a fuertes compromisos por la Justicia Social.

El proceso de validación de los instrumentos se ha realizado a través de un estudio piloto, y mediante el criterio de jueces expertos en Justicia Social que nos permitieron determinar una validez adecuada de contenido y de constructo de los cuestionarios. Los instrumentos presentan también una fiabilidad aceptable que denota coherencia y consistencia interna entre los elementos que lo integran. Tras los análisis de fiabilidad y validez, se ha observado que los dilemas que componen los cuestionarios son consistentes y constituyen un concepto unidimensional definido a partir de los tres componentes de Justicia Social (Redistribución, Reconocimiento y Representación) que representan un continuo significativo y teóricamente definido.

Las Subescalas de Justicia Social no representan dimensiones aisladas, sino que están interconectadas, e interaccionan entre sí compartiendo muchos de sus planteamientos. Con los instrumentos elaborados, se ha observado que, la mayor parte de problemáticas e injusticias que se producen en la sociedad en general, y en el sistema educativo en particular, incluyen cuestiones que implican elementos de más de una dimensión, por lo 
que es muy complicado aislar cada uno de los dilemas para vincularlos sólo a una de ellas. En relación a esto, Fraser (2008) habla de bidimensionalidad, en el sentido de que una situación de injusticia puede implicar dos dimensiones o incluso las tres.

Por ello, resulta necesario profundizar en la conceptualización teórica y en la estructura interna de cada una de las dimensiones de Justicia Social, incorporando los elementos conceptuales y hermenéuticos generados desde otras disciplinas, que puedan ayudar a contextualizar cada dimensión en el ámbito educativo, sin perder el punto de vista de su interrelación.

Los cuestionarios han sido diseñados con la intención de abarcar una diversidad amplia de opiniones, con distintas opciones de respuesta que reflejan diferentes niveles de Justicia Social para cada uno de los dilemas propuestos. Sin embargo, al tratarse de cuestionarios con alternativas cerradas se restringen las respuestas de los participantes.

Esta dificultad intrínseca de los cuestionarios nos lleva a considerar otra limitación de este estudio, pues la investigación empírica realizada desde un enfoque exclusivamente cuantitativo se debería apoyar de estrategias cualitativas que nos permitan profundizar en los análisis y resultados obtenidos. Por ello, sería conveniente matizar las representaciones de Justicia Social que tienen estudiantes y docentes, complementando los instrumentos de esta investigación con la aplicación de otros métodos, como entrevistas individuales y grupales. A través del diálogo y las declaraciones manifiestas de los sujetos se podrían explorar las opiniones y representaciones de Justicia Social de los participantes, consiguiendo una mayor riqueza interpretativa y comprensión más profunda del fenómeno objeto de estudio.

Sería interesante determinar también la influencia de la formación y las experiencias en las trayectorias vitales de los participantes con la Justicia Social. Para ello, futuros trabajos de investigación deberían avanzar en estas líneas, incluyendo la medición de otras variables como las experiencias previas de aprendizaje sobre temas de Justicia Social y las experiencias de injusticia vividas o presenciadas. Investigaciones previas (Bandura, 1997; O'Brien et al., 2006) muestran que las experiencias formativas en Justicia Social pueden llegar a tener influencias positivas en las representaciones y creencias de autoeficacia en este ámbito. Experiencias directas de opresión, así como el contacto y observación de las injusticias de otros, son factores que también facilitan la implicación en el trabajo por la Justicia Social (Broido, 2000), siendo innegable la importancia que presentan las experiencias tempranas en el desarrollo de un posicionamiento más orientado hacia la Justicia Social (Caldwell y Vera, 2010). Cabe esperar que las personas que se han comprometido previamente con comportamientos activistas obtengan puntuaciones significativamente más altas en las Escalas y Subescalas de Justicia Social (Hurtado, 2007; Nilsson y Schmidt, 2005; Torres-Harding, Siers y Olson, 2012).

Por otra parte, siguiendo a otros autores (Beer et al., 2012) se sugiere analizar el rol de los rasgos o disposiciones de personalidad en el desarrollo de estas representaciones. Sería útil poder explicar los factores personales y sociales que inciden en estas representaciones y actitudes hacia la Justicia Social. Todas estas variables (formación, experiencias personales y rasgos de personalidad) resultarían significativas porque nos permitirían mejorar el poder exploratorio de los instrumentos y observar su influencia en las representaciones de Justicia Social que presentan estudiantes y docentes. 
El desarrollo de herramientas adaptadas y validadas para el análisis de las representaciones de Justicia Social ha supuesto una contribución a la investigación y se espera que puedan ayudar a la realización de futuros trabajos que analicen las representaciones de Justicia Social que presentan estudiantes y docentes. También se deberían realizar estudios longitudinales, para observar la evolución de las representaciones; viendo si mejoran, empeoran o se mantienen los resultados obtenidos a través del tiempo.

Estudios futuros deberían analizar las representaciones de estudiantes y docentes de Justicia Social en distintas muestras y contextos diferentes. Es destacable que hasta el momento se han traducido los cuestionarios a varios idiomas (inglés, portugués, euskera y catalán) con la intención de poder realizar estudios comparativos entre diversos países y regiones. Sin embargo, es necesario adaptar los instrumentos a los entornos específicos, tanto en términos lingüísticos como culturales y contextuales, para poder captar con mayor precisión los matices y variaciones locales que se manifiestan en los distintos ambientes y centros de formación.

Los instrumentos diseñados en esta investigación también pueden ayudar a desarrollar proyectos educativos para la formación de docentes y estudiantes de Educación Secundaria, en el ámbito de una enseñanza que promueva la Justicia Social. Los programas que deseen integrar la Justicia Social en sus currículos pueden usar este marco para plantear preguntas acerca del modo más adecuado de abordar estos temas. Ha sido destacada por otros autores (Beer et al., 2012; Miller et al., 2009) la importancia de las percepciones que tienen las personas para influir en sus compromisos hacia la Justicia Social en los ambientes de formación.

Fomentar en las y los estudiantes el compromiso hacia la búsqueda activa de la promoción de Justicia Social es un objetivo de muchos docentes. Para ello, resulta conveniente desarrollar evaluaciones sobre la orientación y las representaciones de Justicia Social que presentan estudiantes y docentes, ayudando de este modo a determinar las necesidades educativas de programas de Justicia Social que se puedan aplicar en la etapa de Enseñanza Secundaria y en la Universidad. En este sentido, consideramos conveniente evaluar las representaciones que tienen las personas jóvenes sobre Justicia Social para adaptarse a sus distintos niveles de comprensión y poder elaborar programas adecuados para intervenir en Justicia Social.

Como se ha demostrado en estudios previos (Cochran-Smith et al., 2012; Enterline et al., 2008; Lazar, 2012; McDonald, 2005), estas evaluaciones también pueden ser útiles para medir los cambios que manifiestan los estudiantes de estos programas tras su formación. Evaluando las ideas o representaciones que tienen sobre la Justicia Social, se podría valorar la eficacia de las intervenciones en clase, incrementando a su vez una mayor conciencia sobre estas preocupaciones (Torres-Harding et al., 2014). El conocimiento de estas representaciones puede servir a educadoras y educadores para facilitar el diálogo, la reflexión y la acción en torno a actividades relacionadas con la Justicia Social.

Por lo tanto, las investigaciones futuras deben continuar centrándose en cómo estudiantes y docentes conceptualizan lo que significa trabajar activa y colaborativamente por la Justicia Social, examinando cómo las personas pasan de la toma de conciencia y las representaciones de Justicia Social a participar implicándose activamente por el cambio social. 
Como señala Goodman (2000), sólo cuando somos conscientes desde una perspectiva crítica de las desigualdades de la sociedad podremos intervenir sobre las injusticias, y esta promoción de la Justicia Social sólo se podrá conseguir mediante la mejora de las condiciones, situaciones y contextos en los que se (re)producen dichas injusticias, teniendo en cuenta para ello las dimensiones de Redistribución, Reconocimiento y Representación. El interés último que se persigue con este trabajo es promover a través de esta reflexión, actitudes, prácticas y acciones educativas orientadas hacia la lucha por la justicia social, que permitan la superación de las desigualdades y la lucha contra las injusticas en los distintos contextos educativos.

\section{Agradecimientos}

Este trabajo forma parte del proyecto "Escuelas para la justicia social" (ref.: EDU201129114.), financiado por el Plan Estatal de I+D+i del Ministerio de Ciencia e Innovación. Gobierno de España.

\section{Referencias}

Ajzen, I. (1991). The theory of planned behavior. Organizational behavior and human decision processes. Information Systems Research, 6(2), 144-176. https://doi.org/10.1016/0749-5978(91)90020-T

Avendaño, M. (2010). La paridad participativa en la obra de Nancy Fraser. Aequalitas: Revista Jurídica de Igualdad de Oportunidades entre Mujeres y Hombres, 26, 58-70.

Bandura, A. (1997). Self-efficacy: The exercise of control. Freedman.

Barreiro, A., Etchezahar, E. y Prado-Gasco, V. (2014). Creencia global en un mundo justo: Validación de la escala de Lipkus en estudiantes universitarios de la Ciudad de Buenos Aires. Interdisciplinaria, 31(1), 57-72. https://doi.org/10.16888/interd.2014.31.1.4

Beer, A. M., Spanierman, L. B., Greene, J. C. y Todd, N. R. (2012). Counseling psychology trainees' perceptions of training and commitments to social justice. Journal of Counseling Psychology, 59(1), 120-127. https://doi.org/10.1037/a0026325

Bonnycastle, C. (2011). Social justice along a continuum: A relational illustrative model. Social Service Review, 85(2), 267-295. https://doi.org/10.1086/660703

Broido, E. M. (2000). The development of social justice allies during college: A phenomenological investigation. Journal of College Student Development, 41(1), 3-18.

Caldwell, J. C. y Vera, E. M. (2010). Critical incidents in counseling psychology professionals' and trainees' social justice orientation development. Training and Education in Professional Psychology, 4(3), 163-176. https://doi.org/10.1037/a0019093

Chen-Hayes, S. F. (2001). Social justice advocacy readiness questionnaire. Journal of Gay \& Lesbian Social Services, 13(1), 191-203. https://doi.org/10.1300/J041v13no1_13

Cochran-Smith, M., Ludlow, L., Ell, F., O'Leary, M. y Enterline, S. (2012). Learning to teach for social justice as cross cultural concept: Findings from three countries. European Journal of Educational Research, 1(2), 171-198. https://doi.org/10.12973/eu-jer.1.2.171

Colquitt, J. (2001). On the dimensionality of organizational justice: A construct validation of a measure. Journal of Applied Psychology, 86(3), 386-400.

https://doi.org/10.1037/002 1-9010.86.3.386 
Corning, A. F. y Myers, D. J. (2002). Individual orientation toward engagement in social action. Political Psychology, 23(4), 703-729. https://doi.org/10.1111/0162-895X.00304

Cronbach, L. J. (1971). Test validation. En R. L. Thorndike (Ed.), Educational measurement (pp. 234256). American Council on Education.

Cuervo, H. (2012). Enlarging the social justice agenda in education: an analysis of rural teachers' narratives beyond the distributive dimension. Asia-Pacific Journal of Teacher Education, 4O(2), 83-95. https://doi.org/10.1080/1359866X.2012.669829

Dalbert, C., Montada, L. y Schmitt, M. (1987). The belief in a just world as a motive: Validity correlates of two scales. Psychologische Beiträge, 29, 596-615. https://doi.org/10.1037/t19124-000

Dean, J. K. (2009). Quantifying social justice advocacy competency: Development of the social justice advocacy scale (Tesis doctoral). Georgia State University, USA.

Enterline, S., Cochran-Smith, M., Ludlow, L. H. y Mitescu, E. (2008). Learning to teach for social justice: Measuring change in the beliefs of teacher candidates. The New Educator, 4(4), 267290. https://doi.org/10.1080/15476880802430361

Fraser, N. (2008). Scales of justice: Reimagining political space in a globalizing world. Columbia University Press.

Gable, R. y Wolf, M. (1993). Instrument development in the affective domain: Measuring attitudes and values in corporate and school settings. Kluwer Academic Publishers.

George, D. y Mallery, P. (2003). SPSS for windows step by step: A simple guide and reference. 11.0 update. Allyn \& Bacon.

Gewirtz, S. y Cribb, A. (2002). Plural conceptions of social justice: Implications for policy sociology. Journal of Education Policy, 17(5), 499-509. https://doi.org/10.1080/02680930210158285

Goodman, D. J. (2000). Motivating people from privileged groups to support social justice. Teachers College Record, 102(6), 1061-1085. https://doi.org/10.1111/0161-4681.00092

Hurtado, S. (2007). Linking diversity with the educational and civic missions of higher education. The Review of Higher Education, 30(2), 185-196. https://doi.org/10.1353/rhe.2006.0070

Jacott, L., Maldonado, A., García-Vélez, T., Pérez-Manjarrez, E., Sainz, V., Juanes, A., Fernández, A., Seguro, V., Agustín, S. y Plascencia, M. (2019). Social justice in education. Capabilities, well-being and social-justice oriented citizens. En L. Jacott, T. García-Vélez y V. Seguro (Eds.), Education, citizenship and social justice: Innovation, practices and research (pp. 139-149). CiCea.

Jodelet, D. (1993). La representación social: Fenómenos, conceptos y teoría. En S. Moscovici (Ed.), Psicología social II (pp. 469-494). Paidós.

Jornet-Meliá, J. M., Sancho-Álvarez, C. y Bakieva, M. (2015). Diseño y validación del constructo teórico de justicia social percibida por el alumnado en los centros escolares. Revista Internacional de Educación para la Justicia Social, 4(2), 111-126.

Lahlou, S. (2015). Social representations and social construction: The evolutionary perspective of installation theory. The Cambridge Handbook of Social Representations, 193, 210-223. https://doi.org/10.1017/CBO9781107323650.017

Lazar, A. (2012). The possibilities and challenges of developing teachers' social justice beliefs. Online Yearbook of Urban Learning, Teaching, and Research, 13, 33-40. 
Lipkus, I. (1991). The construction and preliminary validation of a global belief in a just world scale and the exploratory analysis of the multidimensional belief in a just world scale. Personality and Individual Differences, 12(11), 1171-1178. https://doi.org/10.1016/0191-8869(91)90081-L

Ludlow, L. H., Enterline, S. E. y Cochran-Smith, M. (2008). Learning to teach for social justicebeliefs scale: An application of Rasch measurement principles. Measurement and Evaluation in Counseling and Development, 40(4), 194-214. https://doi.org/10.1080/07481756.2008.11909815

McCoach, D., Gable, R. y Madura, J. (2013). Instrument development in the affective domain school and corporate applications. Springer. https://doi.org/10.1007/978-1-4614-7135-6

McDonald, M. (2005). The integration of social justice in teacher education: Dimensions of prospective teachers' opportunities to learn. Journal of Teacher Education, 56(5), 418-435. https://doi.org/10.1177/0022487105279569

Miller, M. J., Sendrowitz, K., Connacher, C., Blanco, S., Muñiz de la Peña, C., Bernadi, S. y Morere, L. (2009). College students' social justice interest and commitment: A social-cognitive perspective. Journal of Counseling Psychology, 56(4), 495-507.

https://doi.org/10.1037/a0017220

Moscovici, S. (2001). Social representations. Essays in social psychology. New York University Press.

Murillo, F. J. y Hernández, R. (2011). Trabajar por la justicia social desde la educación. REICE. Revista Iberoamericana sobre Calidad, Eficacia y Cambio en Educación (REICE), 9(4), 3-6.

Murillo, F. J., Hernández, R., Hidalgo, N. y Martínez-Garrido, C. (2014). Elaboración y evaluación psicométrica de la escala de actitudes hacia la justica social en educación (EAJSE). Revista Internacional de Educación para la Justicia Social, 3(2), 215-233.

Nilsson, J. E., Marszalek, J. M., Linnemeyer, R. M., Bahner, A. D. y Misialek, L. H. (2011). Development and assessment of the social issues advocacy scale. Educational and Psychological Measurement, 71(1), 258-275. https://doi.org/10.1177/0013164410391581

Nilsson, J. E. y Schmidt, C. K. (2005). Social justice advocacy among graduate students in counseling: An initial exploration. Journal of College Student Development, 46, 267-279. https://doi.org/10.1353/csd.2005.0030

Novak, M. (2000). Defining social justice. First Things, 108, 11-13.

O’Brien, K., Patel, S., Hensler-McGinnis, N. y Kaplan, J. (2006). Empowering undergraduate students to be agents of social change: an innovative service learning course in counseling psychology. En R. L. Toporek, L. H. Gerstein, N. A. Fouad, G. Roysircar, T. Israel (Eds.), Handbook for social justice in counseling psychology: Leadership, vision, and action (pp. 59-73). Sage. https://doi.org/10.4135/9781412976220.n5

Patterson, N., Doppen, F. y Misco, T. (2012). Beyond personally responsible: A study of teacher conceptualizations of citizenship education. Education, Citizenship and Social Justice, 7(2), 191-206. https://doi.org/10.1177/1746197912440856

Pérez de la Fuente, O. (2011). Escalas de justicia y emancipación: Inclusión, redistribución y reconocimiento. Revista Internacional de Filosofía, 11, 378-391.

Pratt, D. D. (1992). Conceptions of teaching. Adult Education Quarterly, 42(4), 203-220. https://doi.org/10.1177/074171369204200401

Rasinski, K. A. (1987). What's fair is fair-or is it? Value differences underlying public views about social justice. Journal of Personality and Social Psychology, 53(1), 201-211.

https://doi.org/10.1037/0022-3514.53.1.201 
Rawls, J. (1971). A theory of justice. Oxford University Press.

Reason, R. D. y Davis, T. L. (2005). Antecedents, precursors, and concurrent concepts in the development of social justice attitudes and actions. New Directions for Student Services, 110 , 5-15. https://doi.org/10.1002/ss.161

Remesal, A. (2011). Primary and secondary teachers' conceptions of assessment: A qualitative study. Teaching and Teacher Education, 27(2), 472-482. https://doi.org/10.1016/j.tate.2010.09.017

Ritchhart, M. (2002). Development of the Social Activism Beliefs Rating scale (SABR): An instrument to measure psychologists' attitudes toward social activism (Tesis doctoral). Oklahoma State University.

Rubin, Z. y Peplau, A. (1973). Belief in a just world and reactions to another's lot: A study of participants in the national draft lottery. Journal of Social Issues, 29(4), 73-93. https://doi.org/10.1111/j.1540-4560.1973.tbo0104.x

Rubin, Z. y Peplau, L. A. (1975). Who believes in a just world? Journal of Social Issues, 31(3), 65-89. https://doi.org/10.1111/j.1540-4560.1975.tboo997.x

Sainz, V. (2017). Representaciones de la justicia social en profesores y estudiantes de educación secundaria (Tesis doctoral). Universidad Autónoma de Madrid, España.

Sainz, V. y Jacott, L. (2020). What do secondary education students understand about social justice? Students representations of social justice in different regions of Spain. Interchange, 51(2), 157-178. https://doi.org/10.1007/s10780-020-09389-y

Sammut, G. (2015). Attitudes, social representations and points of view. En G. Sammut, E. Andreouli, G. Gaskell y J. Valsiner (Eds.), The Cambridge handbook of social representations (pp. 96-112). Cambridge University Press. https://doi.org/10.1017/CBO9781107323650.010

Sammut, G., Andreouli, E., Gaskell, G. y Valsiner, J. (2015). The Cambridge handbook of social representations. Cambridge University Press. https://doi.org/10.1017/CBO9781107323650

Sandretto, S. (2008). Action research for social justice. Teaching and Learning Research Initiative.

Sen, A. (2009). The idea ofjustice. Penguin. https://doi.org/10.2307/j.ctvjnrv7n

Sepúlveda-Parra, C. (2010). La representación social de la educación y sus implicaciones en la mejora escolar (Tesis doctoral). Universidad Autónoma de Madrid, España.

Sepúlveda-Parra, C., Brunaud-Vega, V. y Carreño González, C. (2016). Justicia social en la escuela: Representaciones de estudiantes de educación secundaria y desafíos para la formación del profesorado. Revista Internacional de Educación para la Justicia Social, 5(2), 109-129. https://doi.org/10.15366/riejs2016.5.2.006

Taylor, C. (1996). Identidad y reconocimiento. Revista Internacional de Filosofía Política, 7, 10-19.

Tikly, L. y Barrett, A. M. (2011). Social justice, capabilities and the quality of education in low income countries. International Journal of Educational Development, 31(1), 3-14. https://doi.org/10.1016/j.ijedudev.2010.06.001

Torres-Harding, S. R., Siers, B. y Olson, B. D. (2012). Development and psychometric evaluation of the social justice scale. American Journal of Community Psychology, 50(1), 77-88.

https://doi.org/10.1007/s10464-011-9478-2 
Torres-Harding, S. R., Steele, C., Schulz, E., Taha, F. y Pico, C. (2014). Student perceptions of social justice and social justice activities. Education, Citizenship and Social Justice, 9(1), 5566. https://doi.org/10.1177/1746197914520655

Wagner, W. (2015). Representation in action. En G. Sammut, E. Andreouli, G. Gaskell y J. Valsiner (Eds.), The Cambridge handbook of social representations (pp. 12-28). Cambridge, Inglaterra: Cambridge University Press.

https://doi.org/10.1017/CBO9781107323650.004

Walker, M. (2006). Towards a capability-based theory of social justice for education policy-making. Journal of Education Policy, 21(2), 163-185.

https://doi.org/10.1080/02680930500500245

Walzer, M. (1983). Spheres of justice: A defense of pluralism and equality. Basic Book.

Young, I. M. (2000). La justicia y la política de la diferencia. Cátedra. 


\section{Anexo. Cuestionario de representaciones de justicia social para profesores (CRJSP)}

Autores: Liliana Jacott, Antonio Maldonado, Vanesa Sainz, Tatiana García-Vélez, Vanesa Seguro, Almudena Juanes, Everardo Pérez-Manjarrez, Santiago Agustín y Antonio Fernández (2020)

A continuación, se presentan una serie de situaciones hipotéticas y 3 posibles alternativas de actuación. Marque con una $\mathrm{X}$ cuál de estas 3 alternativas considera que es más justa.

1. Gandacia es un país en el que viven y trabajan muchas personas que no tienen un conocimiento mínimo del idioma gandés. ¿Cuál de las siguientes opciones te parece la más adecuada?:

A) Para ser ciudadana/ciudadano con todos los derechos se debería tener un conocimiento mínimo del idioma.

B) Para tener derecho a trabajar se debe tener un conocimiento mínimo del idioma.

C) Para ser ciudadana/ciudadano con todos los derechos no debería ser obligatorio tener un conocimiento mínimo del idioma.

2. Andrea tiene 8 años y va siempre al colegio en silla de ruedas. El patio es de arena y su familia solicita que una parte del mismo sea cubierto con material liso y firme, para que sea más fácil moverse y jugar en el patio con otros niños y niñas. La obra es cara. ¿Qué opción apoyarías tú?:

A) Gastar todo el dinero necesario e iniciar las obras en el menor tiempo posible, para que Andrea pueda jugar como los demás.

B) Arreglar al menos la mitad del patio para que pueda jugar.

C) Gastar más en obras que beneficien a la mayoría y buscar una solución alternativa para los casos particulares como éste.

3. Un derecho universal para todas las personas debería ser:

A) Poder acceder a través de internet a cualquier información que esté en la web.

B) Tener un ordenador rápido para poder ver muchos sitios en poco tiempo.

C) El uso de los ordenadores de cualquier sitio (p.ej. el colegio, centros comerciales) para acceder a la red.

4. Ana quiere ser la representante de su clase, pero su tutora cree que debería ser representante otra/otro estudiante con mucho mejores calificaciones que ella. ¿Quién crees que debería ser representante?:

A) Las/los estudiantes mejor valorados por su tutora.

B) Solo deberían ser representantes estudiantes con buenas calificaciones.

C) Cualquier estudiante que sea elegido aunque tenga malas calificaciones.

5. Luisa está en $6^{\circ}$ de primaria y tiene problemas de aprendizaje, lo que le produce muchas dificultades para atender en clase y seguir el ritmo de sus compañeras y compañeros. Por esta razón acude al aula una profesora de apoyo para que le 
sea más fácil entender las cosas y ayudarle en lo que necesita. ¿Qué piensas de esto?:

A) Esto puede retrasar el ritmo de la clase e interferir en el aprendizaje de los demás estudiantes.

B) Es importante que se destinen apoyos extras y ayudas a los niños y niñas con dificultades.

C) Lo que tendrían que hacer la familia de Luisa es llevarla a clases de apoyo por las tardes para reforzar, de manera que pueda seguir el ritmo de la clase.

6. En un centro de educación secundaria se va a nombrar una comisión formada por representantes de las familias y del profesorado que tiene que redactar la normativa de convivencia. Hay un debate sobre cómo tiene que ser la participación de las/los estudiantes en esta comisión. ¿Con cuál de estas opiniones estás más de acuerdo?:

A) Deberían participar sólo el profesorado, equipo directivo y las familias porque son los que tienen más conocimiento del centro y tienen la experiencia de años anteriores.

B) Deberían participar también estudiantes mayores porque tienen experiencia y conocen mejor el centro.

C) Deberían estar representados estudiantes de todos los cursos, ya que cada uno puede aportar un punto de vista diferente.

7. En nuestra sociedad, las mujeres y los hombres que desempeñan el mismo puesto de trabajo no suelen ganar lo mismo. ¿Por qué crees que pasa esto?:

A) Las mujeres ganan menos porque están discriminadas.

B) Las mujeres ganan menos porque generalmente tienen otras obligaciones familiares.

C) Los hombres ganan más porque suelen comprometerse más con su trabajo.

8. Promenia es un país muy pobre que recientemente ha descubierto un yacimiento de petróleo que supondrá un aumento de la riqueza del país. Con los beneficios del petróleo el Gobierno debería:

A) Crear nuevos hospitales y escuelas públicas.

B) Estimular el desarrollo de nuevas empresas y la formación para el empleo.

C) Promover acuerdos con multinacionales para la extracción y comercialización del petróleo.

9. En las elecciones generales de cualquier país deberían tener derecho al voto:

A) Solamente las ciudadanas y ciudadanos que han nacido en ese país.

B) Todas los ciudadanos y ciudadanas que tengan la nacionalidad, hayan nacido o no en ese país.

C) Todos las ciudadanas y ciudadanos que vivan en ese país.

10. Pablo es un niño de $2^{\circ}$ de ESO al que un grupo de su clase molesta y acosa continuamente. Santiago sabe lo que están haciendo sus amigos y amigas y quiere pararlo. ¿Qué es lo que debería hacer?:

A) Decirles que no pueden hacerle eso a Pablo y, si no le hacen caso, pedir ayuda a una persona adulta.

B) No intervenir en las disputas, para no perder a sus amigas y amigos. 
C) Hablar con Pablo para ayudarle a evitar y/o afrontar esas situaciones.

11. El gobierno de Lurtenia está muy preocupado con el consumo de alcohol entre adolescentes y quiere destinar una cuantiosa cantidad de dinero para hacer frente a ese problema en los centros de educación secundaria. ¿Qué crees que es mejor?:

A) Este dinero debería ser utilizado únicamente en aquellos centros en los que ya se ha visto que existe este problema para aplicar programas de tratamiento a los/las estudiantes que consumen mucho alcohol.

B) Debería repartirse ese dinero entre todos los centros para que realizaran obligatoriamente campañas de prevención del consumo de alcohol y tratamiento para los/las que consumen más.

C) Debería hacerse un estudio sobre las necesidades de cada centro y distribuir el dinero en función de sus dificultades y sus proyectos concretos.

12. Para elegir a los representantes políticos de un país, ¿qué te parece más justo?

A) Garantizar que todas las comunidades o regiones de ese país estén representadas.

B) Garantizar que haya un porcentaje mínimo de representantes de cualquier colectivo desfavorecido de ese país.

C) Garantizar que los representantes políticos de ese país puedan ser elegidos por sus méritos y sus capacidades.

13. Tres personas son contratadas para hacer una obra. Una de ellas tiene una leve discapacidad que le hace ir más lento que los demás. ¿Cómo piensas que debe distribuirse el dinero de sus sueldos?

A) Todas las personas deberían cobrar lo mismo porque ocupan el mismo puesto.

B) Cada persona debería cobrar en función de su rendimiento

C) Todas las personas deben cobrar lo mismo y el Estado debe compensar a la empresa económicamente.

14. En tu colegio hay varios alumnos y alumnas que apenas participan en actividades fuera del aula. ¿Qué harías tú para promover su participación?:

A) Que las profesoras y profesores organicemos actividades que les ayuden a participar más.

B) Que los estudiantes de cada clase propongan actividades que les ayuden a participar más.

C) Hablar y pensar con ellos y ellas en otras formas de participación.

15. Rashida es una estudiante musulmana de $3^{\circ}$ de ESO. En la clase de educación física no quiere quitarse el velo a pesar de que el profesor le insiste. ¿Cuál crees que debería ser la posición de la dirección del centro?:

A) Pedirle a ella y a su familia que respeten las normas de la clase.

B) Tratar el caso en la comisión de convivencia para reconsiderar las normas de diversidad cultural.

C) Permitirle que no vaya a las clases de educación física.

16. ¿Cuál de las siguientes formas de gestionar las ayudas económicas internacionales hacia los países más pobres te parece más justa?

A) Favorecer que las empresas multinacionales creen industrias para que contraten a la población local. 
B) Financiar a la población local para que se formen y gestionen sus propias empresas.

C) Que personas expertas y asociaciones independientes sin ánimo de lucro ayuden a los gobiernos a crear infraestructuras sociales y económicas.

17. Algunas chicas y chicos jóvenes piensan que además de votar para elegir gobernantes es necesario convocar consultas para decidir sobre temas muy importantes. ¿Qué piensas que es mejor?:

A) Que se convoquen consultas sobre temas culturales o del medio ambiente.

B) Que sería poco práctico consultar a las ciudadanas y ciudadanos continuamente, porque esa es la función de las personas que gobiernan.

C) Convocar consultas sobre los cambios importantes en los modos de participación y toma de decisiones.

18. Las familias de estudiantes que proceden de otra región, país o religión, deben procurar que sus hijos e hijas:

A) Mantengan su cultura, creencias y costumbres.

B) Se adapten a la cultura, creencias y costumbres predominantes.

C) Decidan por sí mismos lo que creen mejor.

19. Para la asignación de becas, ¿Qué criterio debería tener mayor importancia?

A) La nota media del estudiante.

B) El nivel de ingresos económicos de la familia.

C) Ambos criterios por igual.

20. En un sistema de gobierno democrático, lo imprescindible es que:

A) Se celebren elecciones cada 4 o 5 años para que se cambie o no el gobierno.

B) Exista un parlamento o consejo donde se discutan las leyes entre todas las ciudadanas y ciudadanos o sus representantes y el gobierno.

C) Se respeten todas las libertades y derechos fundamentales de los ciudadanos y ciudadanas de ese país.

21. Para que exista una familia, según tú opinión, lo más importante es que haya:

A) Un matrimonio formado por una mujer y un hombre, con o sin hijas/hijos.

B) Una pareja de personas, de cualquier sexo, que decidan formarla.

C) Un vínculo afectivo entre personas que comparten un lugar de vida común.

22. Vetonia es un país en el que el $\mathbf{3 0} \%$ de los niños y niñas que han nacido en ese país y sus madres y padres no hablan "vetón" (el idioma oficial), sino que hablan "yuso” la lengua oficial de un país vecino (la República Yusa). ¿Cuál de estas propuestas del gobierno de Vetonia te parece mejor para la convivencia en ese país?:

A) Qué todas las niñas y los niños que hablen “yuso" vayan a colegios donde solo se hable ese idioma.

B) Que se enseñen en los colegios los dos idiomas: "vetón” y “yuso" a todas las niñas y los niños.

C) Que haya colegios distintos y que cada familia elija a cuál quiere ir. 
23. Algunas personas no aceptan que las parejas de gays y de lesbianas tengan hijas/hijos. Ante esta situación, ¿qué piensas que es mejor?

A) Para proteger los derechos de los niños y las niñas estas parejas no deberían tener hijas/hijos.

B) Para proteger los derechos de los niños y las niñas, no deberían contarle a nadie cómo es su familia.

C) Para proteger los derechos de los niños y las niñas, el profesorado debería atender a la diversidad de familias que existen.

24. En un colegio se ha planificado una excursión de un día a un importante museo de la ciudad, como actividad extraescolar para dos grupos de estudiantes de $1^{\circ}$ de ESO. El equipo directivo y el equipo de profesores conocen que hay cinco estudiantes cuyas familias no tienen dinero para pagar el coste de esa actividad. ¿Qué deberían hacer?:

A) Que el colegio pague los gastos de los/las estudiantes que no tienen dinero.

B) Elevar un poco el precio de la excursión al resto de estudiantes de los dos grupos para que asistan todos.

C) Asegurarse que los chicos y las chicas que no puedan ir a la excursión trabajen en el centro sobre lo que van a ver en el museo.

25. ¿Por qué crees que a veces se dice que las chicas y chicos jóvenes son apáticos, o que tienen poco interés, a la hora de participar en la vida política y social?:

A) Porque la política no tiene sentido, hay otras cosas más importantes.

B) Porque las personas jóvenes prefieren participar de otras maneras y en otro tipo de espacios.

C) Porque las personas adultas no facilitan la participación activa de las/los jóvenes.

26. En Everenia se está regulando la ley del matrimonio, y en el parlamento hay un debate sobre cuál sería la mejor opción para las parejas de personas del mismo sexo. ¿Cuál crees tú que es la mejor alternativa?

A) Que las personas del mismo sexo puedan casarse y tener los mismos derechos que todos los demás.

B) Las personas del mismo sexo nunca pueden formar un matrimonio.

C) Que a las personas del mismo sexo se les reconozcan algunos derechos, pero no se les permita casarse.

27. Una conocida multinacional del deporte fabrica productos en un país muy pobre, empleando a niños y niñas en las fábricas. ¿Qué piensas de ello?:

A) Permite a las niñas y niños ganar algo de dinero para ayudar a sus familias.

B) Los niños y niñas nunca tendrían que trabajar.

C) Debería permitirse si los niños y niñas prefieren trabajar a estudiar.

28. En algunos países del mundo se censuran ciertos contenidos en internet. En tú opinión son actos que:

A) En algunos momentos pueden ser necesarios para resguardar la paz y la seguridad del país.

B) Es imprescindible que los países desarrollen leyes sobre qué contenidos se pueden publicar en la red. 
C) Limitan los derechos universales de expresión y participación.

29. En relación con los impuestos, ¿qué te parece mejor?:

A) Todas las personas que viven en el mismo país deberían pagar los mismos impuestos.

B) Las personas deberían pagar más impuestos en función de su riqueza.

C) Nadie debería pagar impuestos.

30. Si se pudiera construir una “Justicia Universal”, ¿cómo debería hacerse?:

A) Las organizaciones internacionales como la ONU deberían elaborar leyes que fueran de aplicación universal.

B) Que se tenga en cuenta la opinión de todos los ciudadanos y ciudadanas de los distintos países a través de las asociaciones que defienden este objetivo.

C) Que se promuevan acuerdos entre los gobiernos de aquellos países que comparten las mismas raíces culturales.

31. En relación con la toma de decisiones de las actividades extraescolares que se realizan durante el curso fuera del horario escolar (actividades artísticas, deportivas, de idiomas, etc.):

A) Las actividades extraescolares siempre las deben decidir las familias porque son ellos los que mejor conocen a sus hijas e hijos

B) A partir de los últimos cursos de primaria ya deben decidir los estudiantes.

C) Los estudiantes siempre deben decidir las actividades que quieren realizar.

32. En la actualidad la enseñanza es obligatoria y gratuita hasta los 16 años. Desde su punto de vista que opción de las siguientes proporciona mayores garantías de justicia social.

A) La enseñanza obligatoria y gratuita debe abarcar hasta la mayoría de edad, proporcionando en cada etapa el desarrollo de las capacidades y la satisfacción de las necesidades formativas de los estudiantes.

B) La enseñanza obligatoria y gratuita debería abarcar hasta los 14 años para poder dar respuesta a los alumnos que no desean continuar con sus estudios e incorporarse al mundo laboral lo antes posible.

C) La enseñanza obligatoria y gratuita debe abarcar hasta los 16 años dado que no es imprescindible que todos los alumnos realicen estudios más allá de esta etapa.

33. Cuál es su opinión respecto al debate entre comprensividad y diversificación temprana.

A) En las etapas educativas obligatorias, es imprescindible la diversificación de los contenidos para los diferentes estudiantes con distintas capacidades o talentos.

B) En las etapas educativas obligatorias la comprensividad debe ser un criterio básico de equidad educativa.

C) En las etapas educativas obligatorias debe existir un equilibrio entre la comprensividad y la diversificación temprana de los contenidos en función de las diferentes capacidades de los estudiantes.

34. En un Ayuntamiento hay una gran demanda de plazas de educación secundaria que apenas son cubiertas por los tres centros financiados con fondos públicos que existen (dos públicos y uno concertado). Además, hay un cuarto centro 
totalmente privado que tiene un gran número de solicitudes. En este contexto, lo más justo socialmente sería:

A) Aumentar provisionalmente la ratio en los centros financiados con fondos públicos, mientras se construye un tercer centro público.

B) Conceder financiación con fondos públicos al centro privado para que se convierta en concertado.

C) Subvencionar a las familias de los alumnos que acuden al centro totalmente privado para compensar su esfuerzo económico adicional.

35. La familia de Elena quiere que ella estudie la ESO en un colegio solo para chicas. Desde un punto de vista educativo, ¿qué opción te parece más justa socialmente?

A) El Estado debe apoyar con fondos públicos este tipo de centros para garantizar que aquellas familias que deseen que sus hijas/hijos estudien en un colegio separado por sexos puedan hacerlo.

B) El Estado no debe apoyar con fondos públicos este tipo de centros, ya que la educación separada por sexos no promueve la igualdad ni la convivencia entre mujeres y hombres.

C) El Estado no debería autorizar la existencia de centros que separan en función del sexo porque no promueven el pleno desarrollo de chicas y chicos.

36. En tu opinión, para que los estudiantes con problemas de aprendizaje que tengan adaptaciones curriculares significativas obtengan el Título de Educación Secundaria Obligatoria:

A) Deben tener las competencias y los conocimientos mínimos, que se requieren igualmente para el resto de estudiantes.

B) Deben haber mejorado significativamente respecto a sus competencias y conocimientos anteriores.

C) Deben realizar otro itinerario formativo que requiera otro tipo de competencias y conocimientos.

37. En relación con los libros de texto y el material escolar:

A) Las familias deben proveer a sus hijos del material escolar y de los libros de texto necesarios.

B) Los centros educativos en colaboración con las familias deben llevar a cabo un sistema de préstamo de libros para todos sus alumnos.

C) La Administración Educativa debe dotar a las familias más necesitadas del material escolar y los libros de texto necesarios para el curso escolar.

38. Respecto al bachillerato de excelencia. ¿Cuál de las siguientes medidas te parece más adecuada para hacer frente a esta situación?

A) El Estado debería apoyar la creación de "bachilleratos de excelencia" para los mejores estudiantes de ESO, en donde cuenten con los mejores docentes y medios tecnológicos más avanzados para potenciar un mejor desarrollo de sus capacidades.

B) La creación de este tipo de bachilleratos en los que se divide a estudiantes según su rendimiento académico aumenta las desigualdades, dado que se abandona a aquellos que más apoyo necesitan. 
C) En vez de crearse bachilleratos de excelencia se debería agrupar a los estudiantes en función de su rendimiento académico, con el objetivo de elevar el desempeño promedio.

39. Un profesor de Educación Secundaria se encuentra un sábado por la calle a dos estudiantes del centro que son pareja. Están discutiendo y uno de ellos tiene comportamientos claramente abusivos hacia su pareja. Además de otras posibles actuaciones ¿Qué debería hacer ese profesor en su centro educativo?

A) Comentar en clase abiertamente este tipo de problemas sin aludir explícitamente a los alumnos implicados para prevenir conductas de riesgo similares.

B) No debería comentarlo ya que el suceso ha ocurrido fuera del centro y se debe respetar la intimidad de los estudiantes.

C) Solo debería informar al Departamento de Orientación y/o al tutor para que aborden el problema.

\section{Breve CV de las autoras}

\section{Vanesa Sainz}

Profesora a tiempo completo en la Facultad de Educación y Psicología de la Universidad Francisco de Vitoria. Licenciada en Psicología por la Universidad Complutense de Madrid. Doctora en Educación, Experta en Docencia Universitaria y Especialista en Orientación Educativa por la Universidad Autónoma de Madrid. Merecedora de una beca de concurrencia competitiva por el Programa de Formación al Profesorado Universitario del Ministerio de Educación, Cultura y Deporte (FPU 12-01510) durante los cursos 20132017. Realización de dos estancias predoctorales en London Metropolitan University y en Ottawa University. Desarrollo de la docencia universitaria y la investigación en las áreas de Justicia Social, Desarrollo Humano, Psicología, Educación y Metodología. ORCID ID: https://orcid.org/0000-0002-8897-3389. Email: vanesa.sainz@ufv.es

\section{Liliana Jacott}

Profesora Titular de la Facultad de Formación de Profesorado y Educación en la Universidad Autónoma de Madrid. Sus líneas de investigación se han desarrollado en los últimos años en el ámbito de la educación para la ciudadanía, el desarrollo humano y la educación para la justicia social. Actualmente, su tarea investigadora está dirigida al estudio del desarrollo humano y de las capacidades desde una perspectiva de justicia social, y de las representaciones sobre la justicia social en distintos colectivos. Dentro de un contex to europeo, forma parte de la Red Europea CiCea (Children's Identity \& Citizenship European Association). Actualmente es coordinadora de la Línea de investigación "Desarrollo Humano y Justicia Social" dentro del grupo de investigación GICE (Cambio Educativo para la Justicia Social) de la UAM y coordinadora del Área de Investigación de la Cátedra UNESCO en Educación para la Justicia Social de la Universidad Autónoma de Madrid. ORCID ID: https://orcid.org/O000-0002-5826-3693 Email: liliana.jacott@uam.es 